\title{
Design of Promising Working Fluids for Emergent Combined Cooling, Heating, and Power (CCHP) Systems
}

\author{
Andrés Piña-Martinez, Silvia Lasala, ${ }^{*}$ Romain Privat, Véronique Falk, and Jean-Noël Jaubert*
}

Cite This: ACS Sustainable Chem. Eng. 2021, 9, 11807-11824

Read Online

ABSTRACT: Combined cooling, heating, and power (CCHP) systems enable the simultaneous supply of electricity, heating, and cooling, thus meeting the major energy needs of humans in a single device. Conventional CCHP systems consist of the combination of a prime mover, heating, and cooling system, each of them operating with a thermodynamically suitable working fluid. Recently, novel CCHP cycles, based on the use of a single working fluid for the whole operation, have been proposed. Since the choice of the working fluid represents a design challenge in the development of such technologies, in this work, a product design approach for the selection of suitable working fluids for emergent CCHP applications is presented. A database search is implemented to screen about

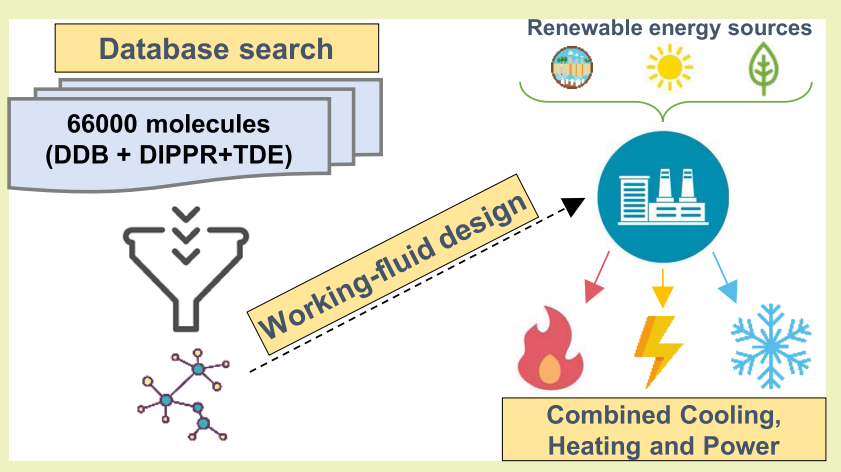
60000 structures included in the DDB, the Design Institute for Physical Properties, and the NIST TDE databases. The screening considers thermodynamic, process-related, constructional, safety, and environmental constraints. Moreover, the $t c$-PR equation of state is used to ensure the quality of the calculation of thermophysical properties and the performance assessment of promising working fluids. This study shows that flammable fluids such as vinylacetylene or HFC-152 have a good potential for CCHP applications. In the case of reinforced safety restrictions, HCFO$1233 \mathrm{zd}(E)$ seems to be an interesting candidate since it is nonflammable and nontoxic.

KEYWORDS: combined cooling, heating, and power (CCHP), trigeneration, product design, working-fluid selection, database search

\section{INTRODUCTION}

According to the International Energy Agency (IEA), "modern economies depend on the reliable and affordable delivery of electricity". ${ }^{1}$ Furthermore, heating arises as the largest energy end-use since it accounts for half of the total energy consumption in the world. Refrigeration and especially cooling demand have been growing steadily since the half of the last century. Therefore, it is undeniable that society these days depends deeply on electricity, heating, and cooling supply, to such an extent that the way to make it more efficient, environmentally friendly, and sustainable constitutes one of the major challenges of this century. It is evident that from the scale of residential to industrial uses, there might be simultaneous needs for electricity, heat, and cold. This opened the way to different technologies such as combined heat and power (CHP) or combined cooling, heating, and power (CCHP) systems.

Conventional $\mathrm{CHP} / \mathrm{CCHP}$ systems consist of different subsystems (prime mover, heat recovery system, and cooling system) for each objective, which, in turn, contain different working fluids and do not operate on the same thermodynamic cycle. Moreover, CHP/CCHP systems operate with singlephase expanders and/or compressors. Recently, Briola ${ }^{2}$ and Briola et al. $^{3}$ presented a novel CCHP cycle, inspired by the patents of Mokadam ${ }^{4}$ and Fabris, ${ }^{5}$ operating with two-phase expanders and compressors. Such a cycle enables the development of an all-in-one device capable of producing electric, heating, and cooling power with a single working fluid. Among the design challenges of this novel CCHP system, the workingfluid selection appears as a key stage of its development.

In the open literature, research on working-fluid design for classical CCHP systems is built on the findings of previous studies conducted on the organic Rankine cycle (ORC). Maraver et al. ${ }^{6}$ worked on the optimization of biomass-fueled ORCs used as prime movers coupled with absorption or adsorption cooling units. They considered promising working fluids used in commercially available ORC units ${ }^{7}$ such as $n$ pentane, octamethyltrisiloxane (MDM), and toluene; as well as non-used in commercial ORC device molecules like $n$-heptane and dodecamethylcyclohexasiloxane (D6). The thermodynamic properties of the fluids were obtained from CoolProp 3.0, ${ }^{8}$ while

Received: May 19, 2021

Revised: July 16, 2021

Published: August 24, 2021 
working-fluid performances were assessed using a process model of the CCHP system. Hong and $\mathrm{Shi}^{9}$ studied solar-driven ORC coupled with absorption chillers. They evaluated HFC-123, HFC-141b, and HCFO-1233zd(E) as working fluids. Performances were obtained from a CCHP model which used RefProp ${ }^{10}$ to calculate thermodynamic properties. Based on previous studies, Al-Sulaiman et al. ${ }^{11}$ selected $n$-octane as a working fluid for solar-driven CCHP systems. Analogously, Huang et al. ${ }^{12}$ decided to evaluate HFC-245fa in biomass-fueled CCHP systems.

By considering working-fluid selection for all-in-one CCHP configurations, it is possible to highlight the work of Briola and co-workers. ${ }^{13}$ They considered the wet pure fluids available in the Aspen Plus 9.0 database and defined technical and environmental constraints. They identified four working fluids (chloroform, methyl iodide, phosphorous trichloride, and thiacyclopropane) and performed a sensitivity analysis of the trigeneration cycle they designed. ${ }^{3}$ Nevertheless, it is possible to point out that since no (or relaxed) toxicological constraints were included in the selection, the four investigated fluids are highly toxic. Moreover, relaxed environmental constraints were used since chloroform and methyl iodide are severely highozone-depleting substances (ODS).

According to the available studies, it is thus possible to identify the following shortcomings in the reviewed CCHP workingfluid design:

- the number of investigated working fluids is rather small and/or influenced by previous studies on ORC configurations;

- a systematic evaluation of thermodynamic and constructional along with toxicological, flammability, and environmental criteria has not been conducted for CCHP systems (by constructional criteria, it is here referred to technical limitations due to the prosaic construction of operation units; in the present, this is essentially the maximum allowed pressure before material failure and the management of air entry in low-pressure systems).

To address these issues, this study aims at implementing a product design approach by screening more than 60000 structures available in the Dortmund Data Bank (DDB), the Design Institute for Physical Properties (DIPPR) database, and the NIST ThermoData Engine 103b (NIST TDE 103b) with the aim of finding suitable candidates for CCHP applications. Furthermore, this work considers thermodynamic, processrelated, environmental, flammability, and toxicity aspects in the selection process as well as performance assessment by means of cycle simulations. To ensure that the performance of CCHP fluids is computed reliably, the translated ${ }^{14,15}$-consistent ${ }^{16,17}$ Peng-Robinson ( $t c$-PR) model $^{18,19}$ is used to estimate saturation and caloric properties.

This paper is organized into six sections. In Section 2, a brief overview of the product design framework is presented. Additionally, the methodologies with the large-space exploration of working fluids for ORC and vapor-compression (VC) refrigeration configurations are introduced. This section is closed with the strengths and weaknesses of the reviewed methodologies, and arguments supporting the choice of a database search are discussed. In Section 3, a detailed description of the CCHP cycle studied in this work is provided. Then, the solution methodology for the exploration of different candidates, including thermodynamic, process-related, environmental, flammability, and toxicity constraints, is presented in
Section 4 . The 2 case studies that we decided to analyze are described in Section 5, and the screening results are discussed in Section 6.

\section{PRODUCT DESIGN FRAMEWORK APPLIED TO THE SELECTION OF WORKING FLUIDS}

According to Moggridge and Cussler, ${ }^{20}$ product design is the process of identifying the best set of candidates that fit the desired product functional criteria. This process can be represented by four principal steps as follows:

(1) Needs. What needs should the product fill?

(2) Ideas. What different solutions/formulations could fill this need?

(3) Selection. Which products are the most promising?

(4) Manufacture. How can the product be made and critically tested?

In turn, Gani ${ }^{21}$ proposes a modified version of Moggridge and Cussler's main stages of product design, well adapted to molecular products:

(1) Needs and goals. What needs/target properties should the product fill?

(2) Generation. What different feasible molecules can be tested?

(3) Selection. Which candidates are the most promising?

(4) Manufacture. How can the product be made?

(5) Performance. Does the product actually satisfy the desired performances?

In the first step, the requirements and the functionalities of the product must be defined. Moreover, it is necessary, and sometimes a hard task, to convert these requirements into quantitative specifications. After this stage, a list of candidates usually referred to as "design space", that could satisfy these needs is generated. Then, the best candidates are selected in stage 3, and finally, in "manufacture," a process design stage is implemented to determine how the product will be made. Performances can be studied using experimental trials or mathematical models. The most common chemical product design methods consist of:

- Experiment-based trial and error: this approach is used when mathematical models for the estimation of the target (desired) properties are not available. Often, past knowledge and experience are required to define the design space. The experimental design approach is frequently used then. This procedure is frequently limited by a fixed amount of chemical, time, and financial resources.

- Model-based search techniques: this approach is used when reliable and validated mathematical models for the estimation of all of the target properties are available. Such models have contributed to the development of the computer-aided molecular design (CAMD) framework. The design space can be quite wide; however, to reduce this space (i.e., the number of candidate molecules), past knowledge and experience may be invoked.

- Hybrid experiment-model-based techniques: this approach is used when only certain properties can be estimated by mathematical models. The most common option is to use models to reduce the list of candidates to a small number of molecules, which may be further evaluated by means of the experiment-based trial and error approach. In such a way, by reducing the design 
space, the time and resources spent on the experimental effort are reduced.

- Databases: Database search is suitable for designing simple molecular products and ingredient selection for some formulated products. Using databases often ensures property reliability and allows a fast generation of the feasible candidates list. ${ }^{22}$ Usually, databases are used for the preselection of candidates and, in a further stage, their performances are assessed with model-based techniques or experiments.

- Heuristics: this approach is supported by heuristic rules (i.e., empirical rules easing the convergence process but are not necessarily optimal) that help to make design decisions, as well as reliable selections. Such rules result from a combination of experience and available knowledge.

Different methods of product design have been used in ORC and VC refrigeration cycles. The literature review presented in the following sections is focused on methodologies with the large-space exploration of working fluids for these types of cycles. For detailed information about experimental or heuristic approaches used in working-fluid selection for ORC or VC refrigeration applications, the reader can refer to the work of Quoilin et al., ${ }^{23}$ Bao and Zhao, ${ }^{24}$ or Motta-Babiloni et al. ${ }^{25}$

2.1. Working-Fluid Design for Vapor-Compression Refrigeration Applications. Early efforts focused on the refrigerant design have been addressed by Joback, ${ }^{26}$ Joback, and Stephanopoulos, ${ }^{27}$ followed by Gani et al. ${ }^{28}$ They described a structured methodology based on a group-contribution (GC) approach for the formation of feasible chemical compounds, prediction of target properties, and screening of candidates. Only constructional and thermodynamic properties were considered. Moreover, the performances of working fluids were not assessed through cycle simulations. Duvedi and Achenie $^{29}$ proposed a mathematical programming-based approach for CAMD and included for the first time environmental constraints represented by the ozone depletion potential (ODP) for chlorofluorocarbons (CFC). Ourique and SilvaTelles, ${ }^{30}$ Marcoulaki and Kokossis, ${ }^{31}$ Sahinidis et al., ${ }^{32}$ and Samudra and Sahinidis ${ }^{33}$ studied the problem of refrigerant design but they were more focused on new optimization approaches for CAMD. Particularly, Sahinidis et al. ${ }^{32}$ pointed out that current approaches (until 2003) used mostly thermodynamic objectives to retrofit refrigeration systems, i.e., to design molecules with properties similar to those of the existing compounds. Moreover, they recognized that properties such as flammability, toxicity, ozone depletion, and chemical stability were difficult to predict, which precluded them from being included in CAMD approaches. In 2012, Kazakov et al. ${ }^{34}$ presented computational tools to screen potential candidates for VC refrigeration cycles. They were able to compute the global warming potential (GWP) and the lower flammability limit for more than 56000 compounds from the PubChem database. Additional filters such as critical temperature, toxicity, and stability were included, and they came up with a list of about 1200 fluids, which were further studied by McLinden et al. ${ }^{35}$

2.2. Working-Fluid Design for ORC Applications. Extensive research has been focused on working-fluid design for ORCs. In 2010, Papadopoulos et al. ${ }^{36}$ proposed for the first time an approach based on CAMD (model-based) for the systematic design and selection of optimal working fluids for low-temperature ORC systems operating between 90 and 20-
$25{ }^{\circ} \mathrm{C}$. They included 15 target properties related to thermodynamic, environmental, safety, and process aspects. They came up with 44 potential working fluids, which they classified into conventional and unconventional molecules. Palma-Flores et al. ${ }^{37}$ used the CAMD approach (model-based) to find new compounds with the potential of being suitable working fluids in ORC processes for waste energy recovery from low-temperature heat sources. The design space consisted of $8.2178 \times 10^{9}$ possible combinations of functional groups to form a molecule. They identified 32 potential working fluids, whose performances were further studied using ASPEN PLUS for ORC simulations. Another CAMD-based approach for the design of optimal working fluids for ORC applications was developed by Lampe et al. $^{38}$ They used the perturbed-chain statistical associating fluid theory (PC-SAFT) equation of state as a thermodynamic model. They used a GC method to calculate, from the molecular structure, the PC-SAFT pure-component parameters: segment number $(m)$, segment diameter $(\sigma)$, and segment energy parameter $(\epsilon / k)$. Preißinger et al. ${ }^{39}$ conducted a database search and screened about 72 million chemical structures contained in the PubChem database by applying the COSMO-RS methodology. They evaluated ORC configurations for waste heat recovery from passenger cars and trucks. The authors implemented a scoring system for each working fluid considering criteria related to thermodynamic, constructional, safety, and environmental aspects. In 2020, Bowskill et al. ${ }^{40}$ proposed a computer-based method for the integrated process and working-fluid design for organic Rankine cycles. The approach is combined with the use of the predictive SAFT- $\gamma$ Mie group-contribution methodology for thermophysical property calculations. This enabled them to study 58960 prospective fluids and their capabilities for three case studies.

2.3. Strengths and Weaknesses. Whether CAMD or database search approaches were used for ORC or VC refrigeration applications, the strengths and weaknesses of both methodologies do not depend on the studied system. For instance, the CAMD framework offers the largest design space and the possibility to find global optimal solutions. Nevertheless, the lack of reliable property models implemented in CAMD tools, for all of the considered chemical families, may lead to the exclusion of environmental or safety targets, which are extremely important for the working-fluid design. On the other hand, database search does not provide the largest possible design spaces and, thus, may miss potential candidates but enables the fast generation of feasible candidate lists. Moreover, by combining different databases, it is possible to include more target properties in the design approach.

Recognizing the forces and limitations of CAMD and database search methodologies, it is considered nevertheless that for the purpose of this work, the latter offers the best tradeoff between the design space and considered target properties.

\section{CCHP CYCLE DESCRIPTION}

In this work, a simplified version of the CCHP cycle proposed by Briola $^{2}$ in his patent is considered. This cycle operates with a single working fluid and allows expansions and compressions to take place in the single-phase regions as well as in the two-phase domain. This section describes the interest of going from power to (heating + power) and (heating + power + cooling) systems. This transition is depicted with an ideal Rankine cycle, and the required modifications that enable such a cycle to become a CCHP cycle operating with a single working fluid. 
Note to the Reader: The way of analyzing the different cycle configurations in this section is mainly graphical and is supported with temperature-entropy $(T-s)$ diagrams. Furthermore, all of the considered cycles are ideal, i.e., they do not involve any internal irreversibilities. In consequence, the specific entropy changes of the working fluid during a process are only due to heat transfer. Considering this, the amount of specific heat exchanged is given by

$$
\delta q_{\text {rev }}=T \mathrm{~d} s
$$

In consequence, in a $(T-s)$ diagram, a given amount of heat can be represented as the area below the curve of the corresponding process. Keeping this in mind, a heat-addition process follows the direction of increasing specific entropy, a heat-rejection process follows the direction of decreasing specific entropy, and an adiabatic process takes place at constant specific entropy. To illustrate the usefulness of $(T-s)$ diagrams, the derivation of the expression for the net work and the thermal efficiency of a Carnot cycle is presented in Appendix A1 in the SI.

3.1. From Power to Combined Heating and Power. An internally reversible Rankine cycle is shown in Figure 1. The
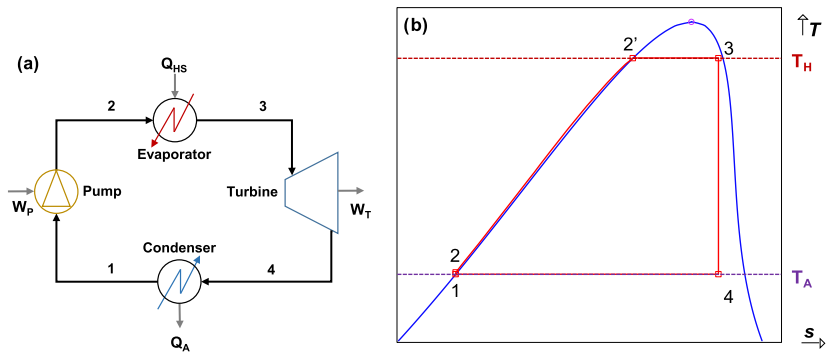

Figure 1. (a) Schematic view of an ideal Rankine cycle. (b) Sketch to the corresponding temperature-entropy diagram.

fluid in a liquid state is compressed isentropically by a pump (12 ), heated at constant pressure in an evaporator (2-3) until partial or total vaporization is reached, expanded isentropically in a turbine (3-4), and condensed at constant pressure (4-1) to the initial state.
Now, consider a performance indicator (PI) that accounts for the useful effect generated in the surroundings. Generally speaking, useful effects can be the net work done and/or the cooling and heating effects provided to the surroundings. This indicator can be defined as the ratio between the useful effects generated by the machine and the energy supplied to the engine for its operation.

$$
\text { PI } \equiv \frac{\text { useful effects }}{\text { supply }}
$$

For the machine considered in Figure 1, two cases can be analyzed. In the first case, $T_{\mathrm{A}}$ is the ambient temperature, and no useful heating effect is provided to the surroundings. In consequence, the machine only produces useful work and the performance indicator is much lower than $100 \%$. For the second case, let $T_{\mathrm{A}}$ be higher than the ambient temperature and consider that heat is provided to an end-user at $T_{A}$. Now, the machine provides two useful effects: power and heat. It is thus a combined heat and power ( $\mathrm{CHP})$ system, and the performance indicator becomes

$$
\mathrm{PI}=\frac{\left|w_{\text {net }}\right|+\left|q_{\mathrm{A}}\right|}{q_{\mathrm{HS}}}=100 \%
$$

For this type of engine, the performance indicator is also called the energy utilization factor (EUF).

The CHP system just described before is not practical because it cannot adjust to the variations in power and heat loads. A more practical CHP configuration is shown in Figure 2. Now, the expansion (3-4) of the original cycle (Figure 1) is split into two stages $(3-4)$ and $(5-6)$, while the process $(4-5)$ is intended to provide the required specific heating power $\left(q_{\mathrm{M}}\right)$ at $T_{M}$.

To have a look at the impact of the variations of specific heat loads and the temperature at which it is required, consider the two superposed cycles shown in Figure 3. Let the cycle formed by the states $\left(1-2-2^{\prime}-3-4-5-6-1\right)$ be the cycle $A$, and that formed by states $\left(1-2-2^{\prime}-3-4-5^{\prime}-6^{\prime}-1\right)$ be the cycle $B$. The specific net work output of cycles $A$ and $B$ is given by the area of polygons 1$2-2^{\prime}-3-4-5-6-1$ and $1-2-2^{\prime}-3-4-5^{\prime}-6^{\prime}-1$, respectively. In turn, as shown in Figure 4, the heating power $\left(\left|q_{M}\right|\right)$ for cycle A is given by the area of the polygon 4-5-B-D, while that of cycle $B$

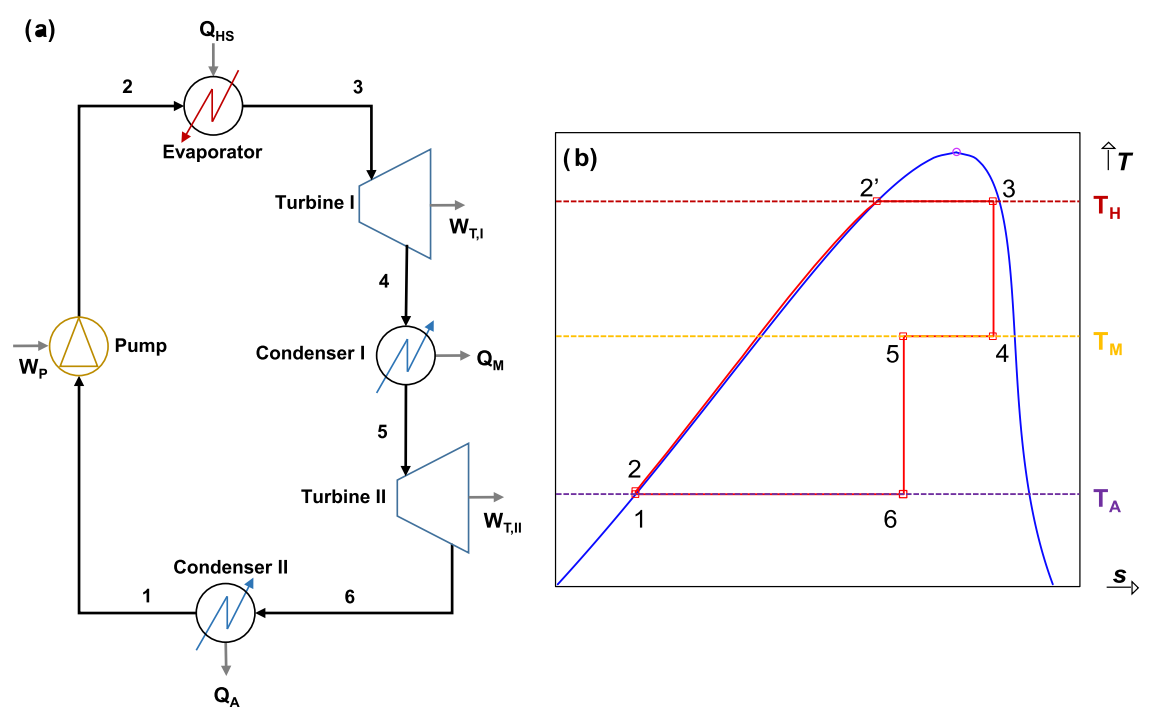

Figure 2. (a) Schematic view of an ideal CHP cycle. (b) Sketch of the corresponding temperature-entropy diagram. 


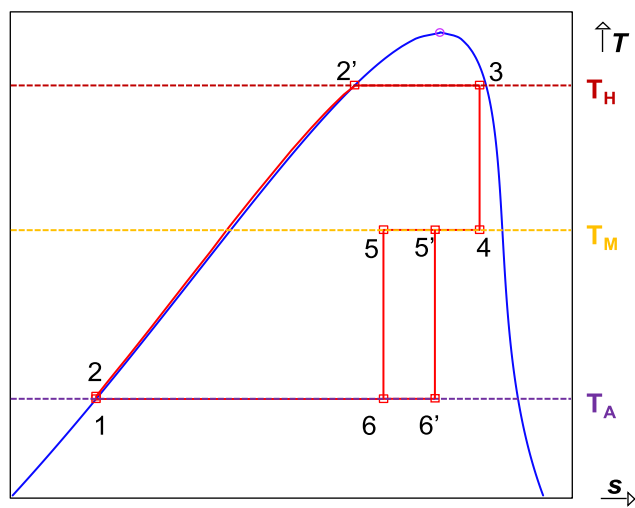

Figure 3. Sketch of the temperature-entropy diagram of two CHP cycles: cycle A (1-2-2'-3-4-5-6-1) and cycle B (1-2-2'-3-4-5'-6'-1).

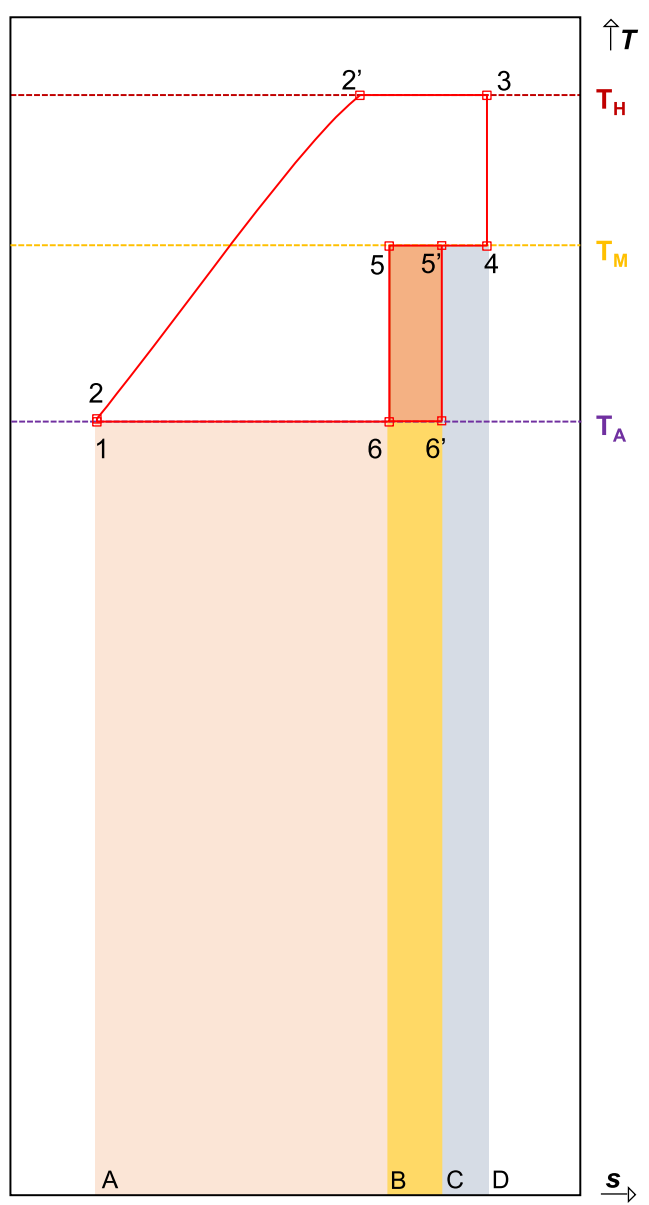

Figure 4. Enlarged temperature-entropy diagram for the CHP cycles considered in Figure 3.

corresponds to the area of the polygon $4-5^{\prime}-\mathrm{C}-\mathrm{D}$. It is thus possible to observe that the specific net work output of cycle $A$ is lower than that of cycle $\mathrm{B}$, while the heating power of the former is greater than that of the latter. In terms of EUF $\left(\left|w_{\text {net }}+q_{\mathrm{M}}\right|\right)$ $\left.q_{\mathrm{HS}}\right)$, it is found that $\mathrm{EUF}_{\mathrm{A}}>\mathrm{EUF}_{\mathrm{B}}$ since the gain of specific net work output of cycle B $\left(5-5^{\prime}-6-6^{\prime}\right)$ is lower than the increase of specific heating power provided by cycle A (5-5'-B-C). It is thus demonstrated graphically that $\mathrm{CHP}$ machines are characterized by a higher thermal efficiency when they operate in a regime in which the demand for heating power is greater than that of electric power.
Now, the case shown in Figure 5 is examined. Let the cycle formed by the states (1-2-2'-3-4-5-6-1) be the cycle A, and that

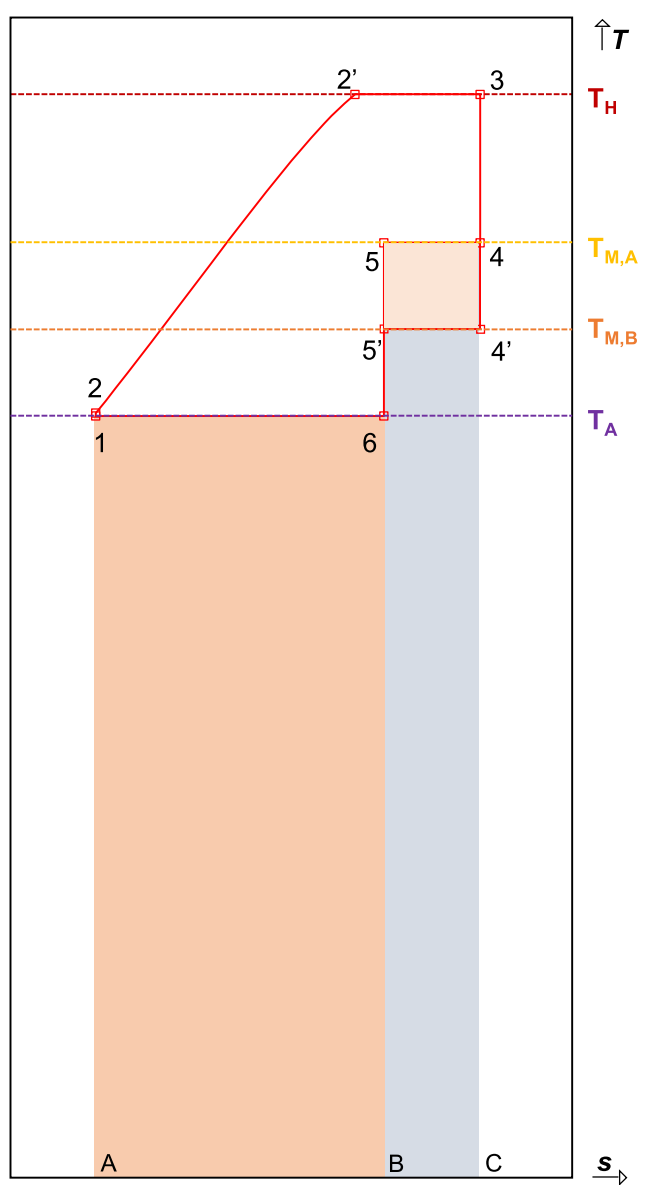

Figure 5. Enlarged temperature-entropy diagram for two CHP cycles providing heat at different temperatures.

formed by states $\left(1-2-2^{\prime}-3-4^{\prime}-5^{\prime}-6-1\right)$ be the cycle $B$. The only difference is that $T_{\mathrm{M}, \mathrm{A}}>T_{\mathrm{M}, \mathrm{B}}$. In this case, it is observed that as for the previous scenario: $\left|w_{\text {net }}\right|_{A}<\left|w_{\text {net }}\right|_{B}$ and $\left|q_{M}\right|_{A}>\left|q_{M}\right|_{B}$. Nevertheless, the EUF of both cycles is the same. Indeed, $\left|q_{\mathrm{A}}\right|$ and $q_{\mathrm{HS}}$ are the same in the two cycles so that the useful specific energy $\left|w_{\text {net }}+q_{M}\right|$ is not modified not to break the first law that simply writes: $q_{\mathrm{HS}}=\left|w_{\text {net }}+q_{\mathrm{M}}+q_{\mathrm{A}}\right|$. Such useful specific energy, defined by the area of the polygon 1-2-2'-3-C-B-6-1 in Figure 5, thus remains constant in spite of the relative changes in $\left|w_{\text {net }}\right|$ and $\left|q_{\mathrm{M}}\right|$. In other words, the loss (or gain) in $\left|w_{\text {net }}\right|$ for one cycle is compensated by the gain (or loss) in $\left|q_{\mathrm{M}}\right|$ by the other.

The operation of an ideal CHP system has thus been presented. It is observed that the EUF depends on the relation between the mechanical and thermal power required by the enduser. In the next section, the addition of a refrigeration subcycle is described. For this purpose, the working fluid should be able to absorb heat at a temperature lower than the ambient temperature $T_{\mathrm{A}}$. In addition, the cooling effect generated by the refrigeration subcycle and its impact on the EUF is discussed.

3.2. CCHP Configuration. To move from a CHP to a CCHP cycle, a part of the cycle must be dedicated to refrigeration (i.e., absorption of specific heat at a temperature $T_{\mathrm{C}}$ lower than $T_{\mathrm{A}}$, the temperature of the environment). To do so, consider that the fluid exiting from the condenser of the $\mathrm{CHP}$ cycle (see point 1 in Figure 2) is directed toward a refrigeration 


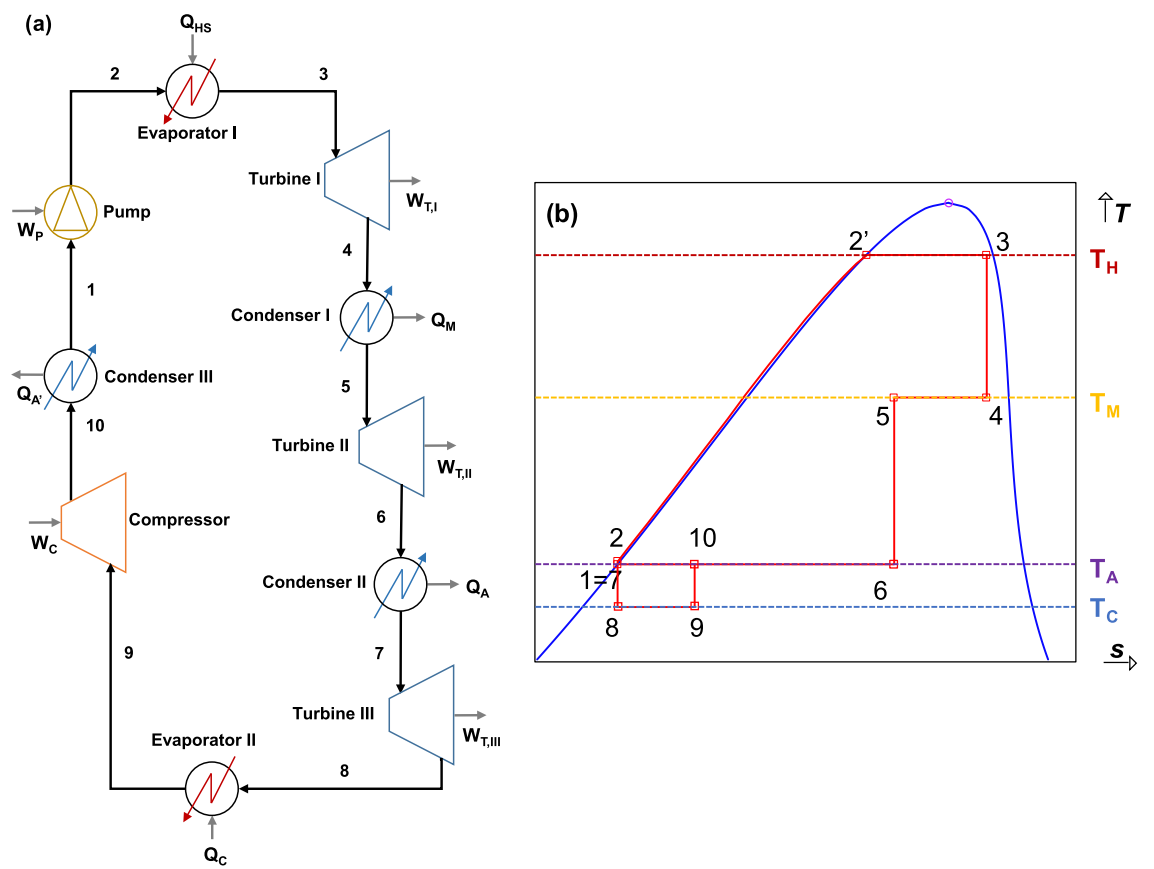

Figure 6. (a) Schematic view of an ideal CCHP cycle and (b) Sketch of the corresponding temperature-entropy diagram.

subcycle. In the CCHP cycle, this point is called “7”. Therefore, instead of pumping the working fluid back to the evaporator as done in the CHP configuration, the fluid is expanded isentropically $(7-8)$, heated at constant pressure in an evaporator (8-9), compressed isentropically (9-10), and, finally condensed at constant pressure (10-1). The amount of specific heat absorbed isothermally by the working fluid from the low-temperature source at $T_{\mathrm{C}}$ represents a cooling effect in the surroundings. The CCHP configuration is shown in Figure 6.

Even if there is only one fluid flowing in the cycle, it is possible to distinguish a CHP subcycle (1-2-2'-3-4-5-6-1), responsible for the supply of electric and heating power, and a cooling subsystem (7-8-9-10), thus defining a CCHP cycle. Part of the power output of the CHP is used to supply the required power input of the cooling system. Therefore, the net output power of the CCHP systems becomes

$$
\begin{aligned}
\left|w_{\text {net }}\right|_{\mathrm{CCHP}} & =\left|w_{\text {net }}\right|_{\mathrm{CHP}}-w_{\text {net }} \text { cooling } \\
& =\left[\left|w_{\mathrm{T}, \mathrm{I}}+w_{\mathrm{T}, \mathrm{II}}\right|-w_{\mathrm{P}}\right]-\left(w_{\mathrm{C}}-\left|w_{\mathrm{T}, \mathrm{III}}\right|\right)
\end{aligned}
$$

It is clear that the specific net work supplied by the CCHP system is lower than that of the CHP one. Graphically, $\left|w_{\text {net }}\right|_{\mathrm{CHP}}$ is the area of the polygon (1-2-2'-3-4-5-6-1), whereas $w_{\text {net } t_{\text {coling }}}$ is the area of the rectangle (7-8-9-10) so that the difference of both these areas is the net work supplied by the CCHP system. Similarly, the useful effects generated by the CCHP cycle are not the same as for a CHP machine. The EUF of the CCHP cycle is defined as

$$
\mathrm{EUF}_{\mathrm{CCHP}}=\frac{\left|w_{\text {net }}\right|_{\mathrm{CCHP}}+\left|q_{\mathrm{M}}\right|+q_{\mathrm{C}}}{q_{\mathrm{HS}}}
$$

results to be higher than that of the CHP configuration due to the fact that the specific cooling power is added to the useful effects and that the reduction of the CCHP net output specific power is lower than the cooling effect $\left(q_{\mathrm{C}}>w_{\text {net }_{\text {coling }}}\right)$.
3.3. Actual CCHP Operation and Degrees of Freedom. After the description of the ideal CCHP configuration, it is necessary to analyze which variables are specified in the problem and if, at least, it is solvable. For instance, in an actual scenario of trigeneration, most of the time, the required electric, heating, and cooling powers are fixed by the end-users.

To have a simple indication of how many variables need to be specified to make a system of equations solvable, it is possible to perform a degree-of-freedom analysis. It is a simple way to make sure that the number of variables and equations is in balance prior to attempting solution. In general, the degrees of freedom can be expressed as

$$
\mathrm{DF}=n_{\mathrm{var}}-n_{\mathrm{eq}}-n_{\mathrm{spec}}
$$

where $n_{\mathrm{var}}, n_{\mathrm{eq}}$, and $n_{\text {spec }}$ are the number of variables, independent equations, and specified variables, respectively.

The assumptions used for the modeling of the CCHP cycle are:

(1) The system operates in steady-state conditions.

(2) The pressure drop across the heat exchangers is negligible.

(3) The minimum temperature difference between the hot and cold streams (i.e., the pinch point) in heat exchangers is equal to $10 \mathrm{~K}$.

(4) The isentropic efficiencies of the turbines, compressor, and pump are known.

With such information, it is possible to perform the degree-offreedom analysis. There are 37 variables involved in the CCHP model, most of them being introduced in Figure 6:

- Mass flowrate $(\dot{m})$ (1 variable).

- Two independent intensive state variables per stream to define the physical state of the working fluid and all of the other state variables. The present case includes 10 streams and thus 20 variables. Independent state variables mean that a couple of variables can be freely chosen but has to be different from $(T, P)$ when the working fluid is at vapor-liquid equilibrium. 
- Duties of the compressor $\left(\dot{w}_{\mathrm{c}}\right)(1), \operatorname{pump}\left(\dot{w}_{\mathrm{P}}\right)(1)$, expanders $\left(\dot{w}_{\mathrm{T}, \mathrm{I}}, \dot{w}_{\mathrm{T}, \mathrm{II}}, \dot{w}_{\mathrm{T}, \mathrm{III}}\right)(3)$, and heat exchangers $\left(\dot{Q}_{\mathrm{HS}}, \dot{Q}_{\mathrm{M}}, \dot{Q}_{\mathrm{A}}, \dot{Q}_{\mathrm{C}}, \dot{Q}_{\mathrm{A}^{\prime}}\right)(5): 10$ variables.

- The net output power $\left(\dot{w}_{\text {net }}\right)(1)$.

- Specific enthalpies at the exit of the compressor, pump, expanders when they are considered as reversible and adiabatic, i.e., isentropic ( 5 variables). These variables (noted $h_{\mathrm{i}}^{\mathrm{s}}$ ) are involved in the isentropic-efficiency definitions of these operation units and used accordingly to estimate the corresponding actual duties.

The number of independent equations results from:

- Ten independent energy balances (1 per operation unit).

- Five additional relations between isentropic efficiencies and actual duties of the compressor, pump, and turbines.

- One additional relation stemming from the equation of definition of the net output power.

Concerning the specified variables, they are defined as explained hereafter and are summarized in Table 1.

Table 1. Summary of the Specified Variables and Specification Equations for the CCHP System Studied in this Work

\begin{tabular}{|c|c|}
\hline specified variables & specification equations \\
\hline$T_{1}=T_{6}=T_{7}$ & equal to ambient temperature \\
\hline$P_{10}$ & $P_{10}=P^{\mathrm{sat}}\left(T_{7}\right)$ \\
\hline$T_{3}$ & $\begin{array}{l}\text { temperature of the heat source decreased by } 10 \mathrm{~K} \\
\text { (pinch point condition) }\end{array}$ \\
\hline$T_{5}$ & fixed by end-user heating needs \\
\hline$P_{4}$ & $P_{4}=P^{\text {sat }}\left(T_{5}\right)$ \\
\hline$T_{8}=T_{9}$ & fixed at $T_{\mathrm{C}}$ by end-user cooling needs \\
\hline$P_{2}$ & $P_{2}=P^{\mathrm{sat}}\left(T_{3}\right)$ \\
\hline qualities $x_{1}$ and $x_{7}$ & $\begin{array}{l}\text { points } 1 \text { and } 7 \text { are located on the bubble curve, } \\
\text { thus: } x_{1}=x_{7}=0\end{array}$ \\
\hline$\dot{Q}_{\mathrm{M}}, \dot{Q}_{\mathrm{C}}, \dot{W}_{\text {net }}$ & fixed by end-user needs \\
\hline $\begin{array}{l}\text { isentropic efficiencies of } \\
\text { the } 3 \text { expanders }\end{array}$ & see notes \\
\hline $\begin{array}{l}\text { isentropic efficiencies of } \\
\text { the compressor }\end{array}$ & see notes \\
\hline $\begin{array}{l}\text { isentropic efficiencies of } \\
\text { the pump }\end{array}$ & see notes \\
\hline
\end{tabular}

\section{Notes:}

- In this work, it is assumed that the input specific heat comes from renewable thermal sources such as biomass, geothermal, or solar. It is considered that the heat source temperature is at least $160^{\circ} \mathrm{C}$.

- It might have been tempting to specify $T_{10}$, which according to Figure 6 , is equal to the temperature at points 1,6 , and 7 ; however, a variant of this flow diagram would correspond to the case where point 10 is in the gaseous region. If this occurred, we would have $T_{10}>T_{\text {ambient. }}$. It is thus more relevant to introduce a specification on $P_{10}$ rather than on $T_{10}$.

- Similarly, temperature $T_{4}$ could be specified by imposing $T_{4}=T_{5}$ (see Figure 6). However, a variant of this flowsheet would correspond to the case where point 4 is in the gaseous region. If this occurred, we would obtain $T_{4}>$ $T_{5}$. It is thus more relevant to introduce a specification on $P_{4}$ rather than on $T_{4}$.

- Expander: Briola et al., ${ }^{3,13}$ in their proposal, suggest the use of two-phase expanders such as those commercialized by Energent Corp., Electratherm of BEP Europe. The reported isentropic efficiencies range between 0.45 and 0.85 .

- Compressor: Briola et al. ${ }^{3,13}$ found that some prototypes of two-phase compressors may be used. The reported isentropic efficiencies range between 0.35 and 0.75 .

- Pump: The isentropic efficiency of the pump is the same as that used by Briola et al., ${ }^{3,13}$ which ranges between 0.7 to $0.9 .^{40}$

In summary, there are 37 unknown variables, 16 independent equations, and 20 specified variables, resulting in (from eq 6) one degree of freedom, i.e., one variable needs to be fixed prior to attempting solution.

An interesting point to analyze is the outlet of the vapor generator at $T_{3}$. Since in the considered architecture, the fluid should be in the two-phase region at $T_{3}$, the maximum vapor quality at the outlet of the vapor generator $\left(x_{3}\right)$ is equal to 1 (saturated-vapor state). To properly parametrize the studied cycle, one needs to answer the questions:

- how does the choice of $x_{3}$ impact the cycle performances?

- Is $x_{3}=1$ a condition that leads to higher thermal efficiency?

These questions are addressed in Appendix A2 of the SI, in which it is demonstrated that the vapor quality of point 3 should be fixed at the maximum allowed value $x_{3}=1$ to operate at the highest thermal efficiency. In consequence, to fulfill the degree of freedom, it is decided to set the specification for the vapor quality of point 3 at $x_{3}=1$.

Once the problem is set for attempting solution, the 16 calculated variables are:

- the mass flowrate $(\dot{m})$;

- the specific enthalpies of points $2,4,5,6,8,9$, and $10\left(h_{2}\right.$, $\left.h_{4}, h_{5}, h_{6}, h_{8}, h_{9}, h_{10}\right)$;

- the duties of the pump $\left(\dot{W}_{\mathrm{P}}\right), 3$ turbines $\left(\dot{W}_{\mathrm{T}, \mathrm{I}}, \dot{W}_{\mathrm{T}, \mathrm{II}}\right.$, $\left.\dot{W}_{\mathrm{T}, \mathrm{III}}\right)$, and the compressor $\left(\dot{W}_{\mathrm{C}}\right)$;

- the duties of evaporator I ( $\left.\dot{Q}_{\mathrm{HS}}\right)$ and condensers II and III $\left(\dot{Q}_{A}, \dot{Q}_{A^{\prime}}\right)$.

Assuming that the starting point is point 1 , a possible sequence of the calculations is:

- Calculation of $h_{2}: h_{2}=h_{1}+\underbrace{\left(h_{2}^{\mathrm{s}}-h_{1}\right)}_{>0} / \eta_{\mathrm{p}}$.

- Calculation of $h_{4}: h_{4}=h_{3}+\eta_{\mathrm{T}, \mathrm{I}} \underbrace{\left(h_{4}^{\mathrm{s}}-h_{3}\right)}_{<0}$.

- Calculation of $h_{8}: h_{8}=h_{7}+\eta_{\mathrm{T}, \mathrm{IIII}} \underbrace{\left(h_{8}^{\mathrm{s}}-h_{7}\right)}_{<0}$.

At this step, the five following variables: $h_{5}, \dot{m}, h_{6}, h_{9}$, and $h_{10}$ must be simultaneously determined by solving the following system of 5 equations

$$
\left\{\begin{array}{l}
\dot{Q}_{\mathrm{M}}=\dot{m} \cdot\left(h_{5}-h_{4}\right) \\
h_{6}=h_{5}+\eta_{\mathrm{T}, \mathrm{II}} \underbrace{\left(h_{6}^{s}-h_{5}\right)}_{<0} \\
\dot{Q}_{\mathrm{C}}=\dot{m} \cdot\left(h_{9}-h_{8}\right) \\
h_{10}=h_{9}+\underbrace{\left(h_{10}^{s}-h_{9}\right)} / \eta_{\mathrm{c}} \\
\dot{W}_{\text {net }}=\dot{m} \cdot\left[\left(h_{2}-h_{1}\right)+\left(h_{4}-h_{3}\right)+\left(h_{6}-h_{5}\right)\right. \\
\left.\quad+\left(h_{8}-h_{7}\right)+\left(h_{10}-h_{9}\right)\right]
\end{array}\right.
$$


The system can be solved by trial and error, for example. The calculation sequence is the following:

1. Define an initial guess of $h_{5}$ between the specific enthalpy of the saturated liquid at $T_{5}$ and $h_{4}$.

2. Calculate $\dot{m}$ from eq $7 \mathrm{a}$.

3. Calculate $h_{6}$ from eq $7 \mathrm{~b}$.

4. Calculate $h_{9}$ from eq $7 \mathrm{c}$.

5. Calculate $h_{10}$ from eq $7 \mathrm{~d}$

6. Calculate $\left|\dot{W}_{\text {net }}\right|$ from eq $7 \mathrm{e}$ and compare it with the specification $\left|W_{\text {net }}^{\text {spec }}\right|$. If the calculated and specified values of $\left|\dot{W}_{\text {net }}\right|$ do not agree, try another guess for $h_{5}$ and go back to step 2. If $\left|\dot{W}_{\text {net }}^{\text {calc }}\right|<\left|\dot{W}_{\text {net }}^{\text {spec }}\right|$, increase the value of $h_{5}$. Otherwise, decrease the value of $h_{5}$.

Once the system is solved, the calculation of the eight remaining variables is straightforward:

- Calculation of $\dot{W}_{\mathrm{p}}: \dot{W}_{\mathrm{p}}=\dot{m} \cdot\left(h_{2}-h_{1}\right)$.

- Calculation of $\dot{W}_{\mathrm{T}, \mathrm{I}}: W_{\mathrm{T}, \mathrm{I}}=\dot{m} \cdot\left(h_{4}-h_{3}\right)$.

- Calculation of $\dot{W}_{\mathrm{T}, \mathrm{II}}: \dot{W}_{\mathrm{T}, \mathrm{II}}=\dot{m} \cdot\left(h_{6}-h_{5}\right)$.

- Calculation of $\dot{W}_{\mathrm{T}, \mathrm{III}}: \dot{W}_{\mathrm{T}, \mathrm{III}}=\dot{m} \cdot\left(h_{8}-h_{7}\right)$.

- Calculation of $\dot{W}_{\mathrm{c}}: \dot{W}_{\mathrm{c}}=\dot{m} \cdot\left(h_{10}-h_{9}\right)$.

- Calculation of $\dot{Q}_{H S}: \dot{Q}_{H S}=\dot{m} \cdot\left(h_{3}-h_{2}\right)$.

- Calculation of $\dot{Q}_{\mathrm{A}}: \dot{Q}_{\mathrm{A}}=\dot{m} \cdot\left(h_{7}-h_{6}\right)$.

- Calculation of $\dot{Q}_{\mathrm{A}^{\prime}}: \dot{Q}_{\mathrm{A}^{\prime}}=\dot{m} \cdot\left(h_{1}-h_{10}\right)$.

For the two case studies considered in this work, the numerical values of the specified variables are presented in Section 5 .

\section{WORKING-FLUID SELECTION METHODOLOGY}

In Section 2, a general overview of the product design framework has been presented. Such a framework can be applied to different types of products, from coatings and process fluids to solvents and functional devices. In this section, a working-fluid selection methodology for the novel CCHP cycle presented in Section 3 is detailed. The proposed methodology follows the main stages defined by Gani: ${ }^{21}$ (1) needs and goals; (2) generation; (3) selection; (4) manufacture; (5) performance.

A scheme of the product design approach adopted in this work for the selection of suitable working fluids for CCHP applications is presented in Figure 7. The needs and goals are defined in the target properties section. Moreover, the requirements of suitable fluids are described, as well as the estimation methods and bibliographic survey employed to obtain the values of such properties for each candidate. Then, the initial set of candidates is defined by means of database search. Next, the screening order is presented, followed by the performance evaluation, which is supported by the $t c-P R$ equation of state. It is worth noting that Gani et al. ${ }^{41}$ explained that in the case of basic chemicals, such as refrigerants or solvents, for which the end-use properties are often directly related to their molecular structure, the manufacturing process does not affect product properties, and, therefore, stage 4 (manufacture) can be excluded from the design procedure.

4.1. Target Properties. 4.1.1. Critical Temperature. Pure compounds do not condense above the critical temperature. Since one of the main features of the novel CCHP cycle is that the whole operation may take place in the two-phase region, it seems highly intuitive to define critical temperature as the initial criterion of the screening. Considering that the temperature of the hot source is not lower than $160{ }^{\circ} \mathrm{C}$ and a minimum temperature approach of $10 \mathrm{~K}$ in the evaporator, the maximum temperature reached by the working fluid during the operation is set to $150{ }^{\circ} \mathrm{C}$. Consequently, for acceptable performance, the

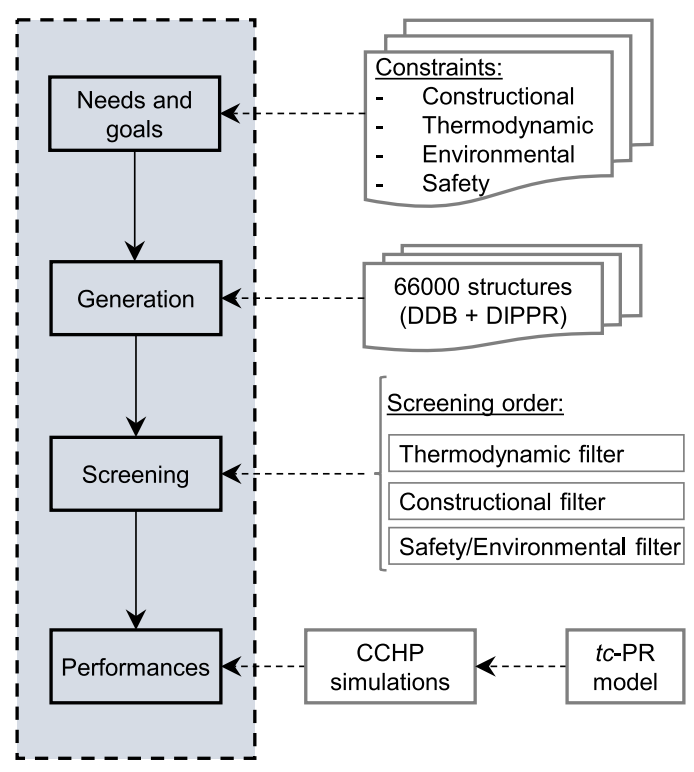

Figure 7. Scheme of the product design approach adopted in this work for the selection of suitable working fluids for CCHP applications.

critical temperature should be high enough to allow a sufficient enthalpy of vaporization of the working fluid in evaporator I. In typical applications such as steam power plants or vaporcompression cycles, the critical temperature is not approached within $40-50{ }^{\circ} \mathrm{C}$, which implies to set the minimum value of the critical temperature to $200{ }^{\circ} \mathrm{C}$. Nevertheless, to avoid making this criterion very stringent, it was decided to force the critical temperature of the fluid to be higher than $155^{\circ} \mathrm{C}$.

4.1.2. Triple-Point Temperature. At low temperatures, freezing within the system should be avoided. For this reason, the triple-point temperature should be lower than the minimum temperature of the cycle $\left(T_{\mathrm{C}}=T_{9}\right)$. The triple-point temperature should not be approached closer than $5 \mathrm{~K}$.

4.1.3. Operating Pressures ( $P^{\text {sat }} @ T_{C}$ and $P^{\text {sat }} @ T_{H}$ ). First, in the evaporator $I$, the saturation pressure at temperature $T_{3}$ cannot be too high because it may result in mechanical failure. Quoilin et al. ${ }^{23}$ suggest that for ORCs, the maximum pressure of the cycle should be 30 bar. However, this limit was set to 35 bar with the aim of avoiding the exclusion of promising candidates at this stage of the screening procedure.

On the other hand, caution should be taken for fluids with an excessively low saturation pressure at $T_{\mathrm{C}}$ since operating at subambient pressures would lead to air entry into the system, resulting in reduced performances of the cycle. The minimum operating pressure (vapor pressure at $T_{\mathrm{C}}$ ) should be higher than $750 \mathrm{mbar}$. This choice is based on the work of Preißinger et al., ${ }^{39}$ who focused on ORC for mobile applications.

4.1.4. Density ( $\rho_{d v} @ T_{C}$ ). In evaporator II, the density of the dry saturated vapor at temperature $T_{\mathrm{C}}$ affects the surface area of the cross-section of the evaporator pipes. In particular, as stated by Lemort et al., ${ }^{23}$ the lower this density, the greater this surface area. It is considered that suitable working fluids should have a saturated vapor density higher than $0.01 \mathrm{~kg} / \mathrm{m}^{3}$ at $T_{\mathrm{C}}$.

4.1.5. Safety (Toxicity, AIT = Autoignition Temperature). Since $n$-pentane, which is a flammable and a potential toxic fluid, is already used in some commercial applications, it is decided that suitable fluids for the novel CCHP cycle should not be more flammable or toxic than $n$-pentane.

Toxicity and flammability information of substances is available from the globally harmonized system (GHS) of 


\section{Pentane}

\section{GHS Classification}

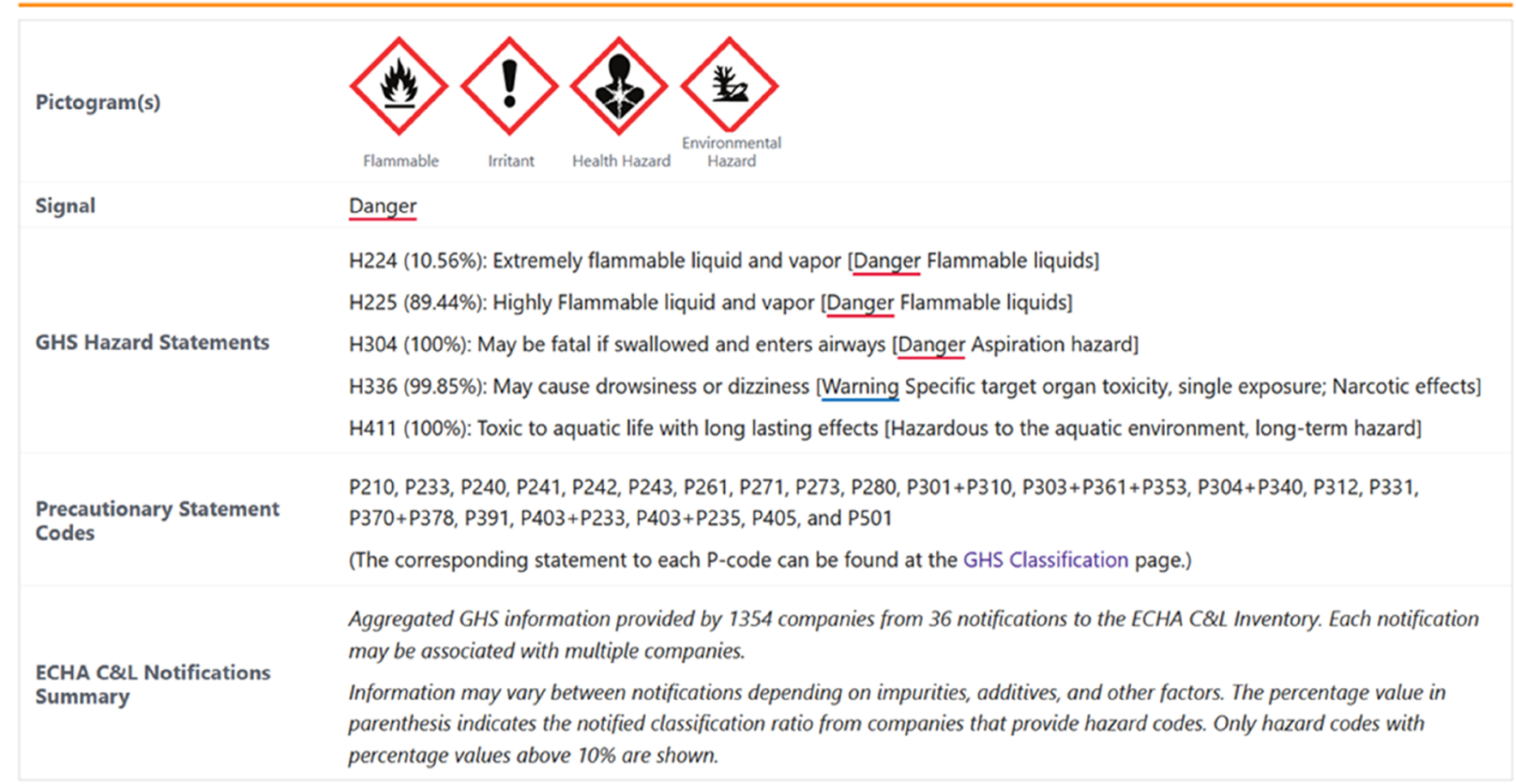

Figure 8. GHS classification of $n$-pentane. Obtained from the public-domain PubChem database of the National Institutes of Health. ${ }^{42}$

classification and labeling of chemicals. The GHS provides harmonized criteria for classifying substances and mixtures according to their health, environmental, and physical hazards. In addition, it includes hazard communication elements, as well as requirements for labeling and safety data sheets. Hazard identification mainly consists of three elements: hazard pictograms, hazard codes ( $\mathrm{H}$-codes), and hazard statements.

Physical hazards are related to explosion, flammability, oxidation, gases under pressure, self-reactivity, and corrosion. They cover codes from H200 to H290. Health hazards include acute toxicity, skin/eye damage, respiratory/skin sensitization, germ cell mutagenicity, carcinogenicity, and reproductive toxicology. They are identified by codes from H300 to H373. Finally, environmental hazards are focused on aquatic organisms and are represented by codes from $\mathrm{H} 400$ to H420.

As an illustration, the GHS classification of $n$-pentane is presented in Figure 8. It is possible to observe the hazard pictograms, codes, and statements. Such information has been gathered in the public-domain PubChem database of the National Institutes of Health. ${ }^{42}$ The database contains more than 100 million compounds but the GHS classification is available for about 150 thousand of them.

Considering the toxicity classification of $n$-pentane as a reference, fluids are not suitable for CCHP applications if they exhibit one or more of the following criteria:

- Carcinogenicity (all categories)

- Mutagenicity (all categories)

- Reproductive effects (all categories)

- Acute toxicity to humans (categories 1, 2, and 3)

- Toxicity to specific human organs (categories SE1, RE1, SE2, and RE2)

- Acute and chronic aquatic toxicity (category 1 )
From the flammability standpoint, since $n$-pentane is classified as an extremely flammable fluid, it is decided not to consider a specific filter for this property. Instead, a filter on autoignition temperature (AIT) is considered. According to the ATEX directive, ${ }^{43}$ the maximum surface temperature of the system may not exceed $80 \%$ of the autoignition temperature of the substance. If this threshold is exceeded, it is still possible to use the fluid, but the required equipment to satisfy safety constraints will be more expensive. Considering that the maximum temperature of the cycle (heat source temperature) is $160{ }^{\circ} \mathrm{C}$, the working fluid should have an autoignition temperature greater than $200{ }^{\circ} \mathrm{C}$. Nevertheless, to provide flexibility concerning the heat source temperature, it is decided to set the threshold at $240{ }^{\circ} \mathrm{C}$.

4.1.6. Compatibility. The working fluid should be compatible with the polymers used in seals and not have a corrosive effect on metals in the system. Information about the latter condition is present in the GHS classification available in the PubChem database. For the screening procedure, the compatibility of the fluid with steel has been imposed.

4.1.7. Global Warming Potential (GWP). With the aim of quantifying and communicating the relative contributions to climate change of emissions of different substances, emission metrics such as global warming potential (GWP) can be used. It has arisen as the default metric for transferring emissions of different non- $\mathrm{CO}_{2}$ gases to a common scale, often called " $\mathrm{CO}_{2}$ equivalent emissions". The GWP is defined as the timeintegration radiative forcing $(\mathrm{RF})$ due to a pulse emission of a given component $i\left(R F_{i}\right)$ relative to a pulse emission of an equal mass of $\mathrm{CO}_{2}\left(\mathrm{RF}_{\mathrm{CO}_{2}}\right)$ 


$$
\operatorname{GWP}_{i}(\mathrm{TH})=\frac{\int_{0}^{\mathrm{TH}} \mathrm{RF}_{i}(t) \mathrm{d} t}{\int_{0}^{\mathrm{TH}} \mathrm{RF}_{\mathrm{CO}_{2}}(t) \mathrm{d} t}
$$

where $\mathrm{TH}$ represents the time horizon, usually set as 20,50 , or 100 years. The GWP for a time horizon of 100 years has been adopted for policy-makers to implement the multi-gas approach as done in the 1997 Kyoto Protocol.

For RF calculation, two input parameters are required: the radiative efficiency and the atmospheric lifetime of the gas. Hodnebrog et al. ${ }^{44}$ provide a comprehensive and consistent analysis of such input parameters required to calculate values of the GWP. The GWP values used for the screening process were obtained from Appendix A of the Scientific Assessment of Ozone Depletion: 2018. ${ }^{45}$ This report includes the GWP values estimated by Hodnebrog et al. as well as those published in the previous Assessment Reports by the Intergovernmental Panel on Climate Change (IPCC). Suitable working fluids for the novel CCHP cycle should have a GWP lower than 150, as established by the EU F-gas regulation. ${ }^{46}$

4.1.8. Ozone Depletion Potential (ODP). The metric used for quantifying the effect of various ozone-depleting substances (ODS) on the ozone layer is called ozone depletion potential (ODP). The ODP is defined as the integrated change in the total ozone per unit mass emission of a specific ozone-depleting substance relative to the integrated change in total ozone per unit mass emissions of CFC-11 (trichlorofluoromethane). As well as for GWP values, ODP was reported from the Scientific Assessment of Ozone Depletion: 2018.

EU regulation No. 1005/2009 on substances that deplete the ozone layer ${ }^{47}$ is the implementation of the Montreal Protocol in European law. It is worth noting that some non-zero ODP molecules are not regulated by that framework. Indeed, as suggested by Eyerer et al. ${ }^{48}$ in 2019 , the substance with the smallest ODP, which is classified as an ODS in the EU regulation No. $1005 / 2009,{ }^{47}$ has an ODP of 0.01 . Considering this information, it is decided to set the cutoff for ODP at $10^{-3}$.

4.2. Chemical Design Space: Data Curation and Preparation. In this work, the experimental data contained in the Dortmund Data Bank (DDB, version 2020 http://www. ddbst.com/ddb.html), the Design Institute for Physical Properties (DIPPR, version 2020), and the NIST ThermoData Engine 103b (NIST TDE 103b) databases are used.

The first step ("prescreening") of the screening process is performed by selecting all of the pure fluids:

- For which the critical temperature $\left(T_{\text {crit }}\right)$ data is available (we indeed search fluids so that $T_{\text {crit }}>155^{\circ} \mathrm{C}$ ).

- For which melting temperature $\left(T_{\text {mel }}\right)$ or triple-point temperature $\left(T_{\mathrm{tp}}\right)$ data is available (one of our target properties is that $T_{\text {mel }}\left(\right.$ or $\left.\left.T_{\text {tp }}\right)<T_{9}\right)$.

- For which the critical pressure $\left(P_{\text {crit }}\right)$ and the acentric factor $(\omega)$ are either available or estimable to enable the application of the $t c$-PR equation of the state that always requires the knowledge of $T_{\text {crit }} P_{\text {crit }}$ and $\omega$. As explained below, the acentric factor may indeed be needed to estimate the parameters $\mathrm{L}, \mathrm{M}, \mathrm{N}$ when they are unknown.

The DDB-2020 database contains experimental data for 66425 molecules. If we apply the prescreening described above, 1415 pure fluids remain, as shown in Figure 9.

Next, the DIPPR-2020 database provides data for nearly 2200 pure fluids and, as shown in Figure 10, 2119 molecules remain if the prescreening described above is applied.

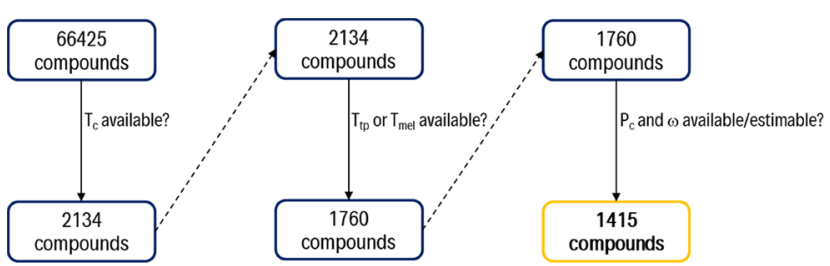

Figure 9. Prescreening on the DDB-2020 database.

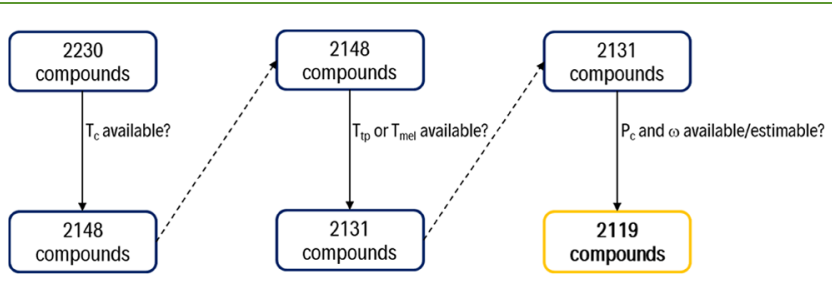

Figure 10. Prescreening on the DIPPR-2020 database.

Finally, the NIST TDE 103b database contains nearly 30220 pure fluids and, as shown in Figure 11, 745 molecules remain if the prescreening described above is applied.

As a conclusion of this prescreening step, the initial count for further screening is 2540 pure fluids: 1129 molecules are only contained in the DIPPR database, 421 molecules are only contained in the DDB database, and 990 molecules are contained in both of them. The 625 compounds coming from the NIST TDE are already contained either in the DDB or the DIPPR databases.

The fact that only 990 pure fluids are present in both DDB and DIPPR databases reflects the complementarity of these databases and, thus, the importance of maximizing the number of different considered databases.

4.3. Thermodynamic Model. As stated before, to ensure the accuracy of thermodynamic property calculations and CCHP simulations, the translated and consistent tc-PR equation of state has been retained. Such a model is acknowledged as an accurate cubic equation of state; it requires 6 componentdependent parameters $\left(T_{\text {crit,exp }}, P_{\text {crit,exp }}, v_{\text {liq,exp }}^{\text {sat }}\left(T_{\mathrm{r}}=0.8\right), \mathrm{L}, \mathrm{M}\right.$, N) and writes:

$$
\begin{aligned}
P(T, v)= & \frac{R T}{v-b}-\frac{a_{\mathrm{c}} \cdot \alpha\left(T_{\mathrm{r}}\right)}{(v+c)(v+b+2 c)+(b+c)(v-b)} \text { with: } \\
& \left\{\begin{array}{l}
\alpha\left(T_{\mathrm{r}}\right)=T_{\mathrm{r}}^{N(M-1)} \exp \left[L\left(1-T_{\mathrm{r}}^{M N}\right)\right] \\
c=v_{\text {liq }}^{\text {sat }-\mathrm{PR}}\left(T_{\mathrm{r}}=0.8\right)-v_{\text {liq, exp }}^{\text {sat }}\left(T_{\mathrm{r}}=0.8\right) \\
\eta_{\mathrm{c}}=[1+\sqrt[3]{4-2 \sqrt{2}}+\sqrt[3]{4+2 \sqrt{2}}]^{-1} \approx 0.25308 \\
a_{\mathrm{c}}=\frac{40 \eta_{\mathrm{c}}+8}{49-37 \eta_{\mathrm{c}}} \frac{R^{2} T_{\text {crit,exp }}^{2}}{P_{\text {crit,exp }}} \approx 0.45724 \frac{R^{2} T_{\text {crit,exp }}^{2}}{P_{\text {crit,exp }}} \\
b=\frac{\eta_{\mathrm{c}}}{\eta_{\mathrm{c}}+3} \frac{R T_{\text {crit,exp }}}{P_{\text {crit,exp }}} \approx 0.07780 \frac{R T_{\text {crit,exp }}}{P_{\text {crit,exp }}}-c
\end{array}\right.
\end{aligned}
$$

It is noticeable that the substance-dependent volume-translation parameter, $c$, is determined, component by component, in order that the translated EoS exactly reproduces the experimental saturated-liquid molar volume at a reduced temperature of 0.8 , $\left[v_{\text {liq,exp }}^{\text {sat }}\left(T_{\mathrm{r}}=0.8\right)\right]$, that is

$$
c=v_{\text {liq }}^{\text {sat } \mathrm{u}-\operatorname{CEoS}}\left(T_{\mathrm{r}}=0.8\right)-v_{\text {liq, } \exp }^{\text {sat }}\left(T_{\mathrm{r}}=0.8\right)
$$

where $v_{\text {liq }}^{\text {sat } \mathrm{u}-\mathrm{CEoS}}\left(T_{\mathrm{r}}=0.8\right)$ is the molar volume calculated with the original (untranslated) $\mathrm{CEoS}$ at $T_{\mathrm{r}}=0.8$. 
Another key feature is the use of the highly flexible Twu $91 \alpha$ function $^{49}$

$$
\alpha(T)=\left(T / T_{\mathrm{c}}\right)^{N(M-1)} \exp \left[L\left(1-\left(T / T_{\mathrm{c}}\right)^{M N}\right)\right]
$$

By determining the 3 parameters $L, M$, and $N$ from a constrained fitting procedure to well-chosen vapor-liquid equilibrium data, the Twu $91 \alpha$-function can pass the consistency test of Le Guennec et al., ${ }^{16}$ thus guaranteeing safe property predictions in both subcritical and supercritical domains. Consistent $L, M$, and $N$ parameters were published by Pina-Martinez et al. ${ }^{19}$ for around 2000 fluids. For other components, they can be determined from second-order polynomial correlations with respect to the acentric factor. ${ }^{19}$

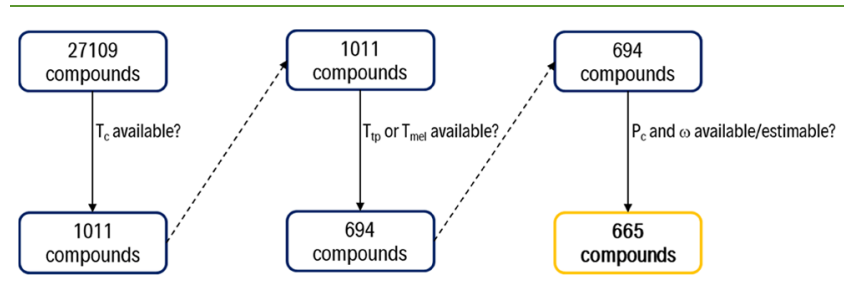

Figure 11. Prescreening on the NIST TDE 103b database.

The key properties that should be properly predicted in this work by the CEoS are vapor pressure, density, enthalpy, and entropy. To ensure the accuracy capabilities of any model, it is necessary to compare its predictions against experimental data. In the case of vapor pressure, density, and enthalpy, plenty of data are available in pure-compound databases. It is worth recalling that in the case of enthalpy and entropy, data of enthalpy and entropy of vaporization are retained. The $t c-P R$ model is able to correlate the vapor pressures with an error of $1 \%$, whereas errors on enthalpy/entropy of vaporization and density are close to $2 \%{ }^{19,50}$ for more than 1700 molecules.

4.4. Screening Procedure. It is worth recalling that among the target properties, critical temperatures, triple-point temperatures, vapor pressures, and densities are available for 2540 pure fluids. The first two properties were directly collected from the DDB and DIPPR databases, and the last two ones were estimated with the tc-PR model. On the other hand, safety, compatibility, and environmental properties are not all available for all of the 2540 fluids. Consequently, it seems necessary to establish a proper order of screening, which guarantees that, at each filter stage, the considered target property is available for the remaining list of fluids.

The first five filters dealt with (1) critical temperature, (2) triple-point temperature, (3) vapor pressure at $T_{\mathrm{C}}$, (4) density at $T_{\mathrm{C}}$, and (5) vapor pressure at $T_{\mathrm{H}}=T_{3}$ because, as mentioned before, they are available for the 2540 molecules of the design space. Next, since toxicity information is reported for 150 thousand molecules in the PubChem database, it was then decided to apply this sixth filter. The next two filters concerned GWP and ODP; they were applied at this stage because even if the measured/calculated GWP and ODP values are not available, it is possible to estimate approximately the GWP or ODP of most of the molecules from their chemical structure. Eventually, compatibility and autoignition temperature (AIT) filters were applied.

The resulting screening order is presented in Table 2 .

4.5. Performance Evaluation. After the fluid screening procedure, the performance of the CCHP configuration operating with the list of selected fluids was investigated. For
Table 2. Screening Order Retained for this Work

\begin{tabular}{cl} 
step & \multicolumn{1}{c}{ criterion } \\
1 & $T_{\text {crit }}$ \\
2 & $T_{\text {tp }}$ \\
3 & $P^{\text {sat }} @ T_{\mathrm{C}}$ \\
4 & $\rho_{\mathrm{dv}} @ T_{\mathrm{C}}$ \\
5 & $P^{\text {sat }} @ T_{\mathrm{H}}$ \\
6 & toxicity \\
7 & GWP \\
9 & ODP \\
10 & AIT \\
11 & material compatibility
\end{tabular}

this purpose, two primary indicators were used: the energy utilization factor (EUF) and the volumetric capacity $\left(Q_{V}\right)$. The EUF, as discussed in Section 3, is defined as the ratio between the useful effects generated by the machine and the specific energy supplied to the engine for its operation. It provides a measure of the energy efficiency (operating cost) of the system. It yields to

$$
\mathrm{EUF}_{\mathrm{CCHP}}=\frac{\left|w_{\text {net }}\right|+\left|q_{\mathrm{M}}\right|+q_{\mathrm{C}}}{q_{\mathrm{HS}}}
$$

The volumetric capacity is defined as the refrigeration capacity per unit of volume of working fluid flowing into the compressor (point 9), and it gives a measure of the equipment size (capital cost). $Q_{\mathrm{V}}$ can be expressed as

$$
Q_{\mathrm{v}}=\frac{\dot{Q}_{\mathrm{C}}}{\left(\dot{m} / \rho_{9}\right)}
$$

Another important indicator is the primary energy saving ratio (PESR). This parameter provides information on how much primary energy is saved using a multigeneration system instead of the separated ones to supply heating $\left(\left|\dot{Q}_{M}\right|\right)$, cooling $\left(\dot{Q}_{C}\right)$, and electric $\left(\left|\dot{W}_{\text {net }}\right|\right)$ power. Note that since different systems are compared and they may operate with different mass flow rates, it is necessary to define PESR using powers rather than specific energy as done for EUF. PESR is thus defined as

$$
\text { PESR }=\frac{\dot{Q}_{\mathrm{HS}, \mathrm{SS}}-\dot{Q}_{\mathrm{HS}, \mathrm{CCHP}}}{\dot{Q}_{\mathrm{HS}, \mathrm{SS}}}=1-\frac{\dot{Q}_{\mathrm{HS}, \mathrm{CCHP}}}{\dot{Q}_{\mathrm{HS}, \mathrm{SS}}}
$$

where $\dot{Q}_{\mathrm{HS}, \mathrm{CCHP}}$ and $\dot{Q}_{\mathrm{HS}, \mathrm{SS}}$ are the amount of energy per unit of time from the heat source required by the CCHP system and separated systems (SS) to provide electric, heating, and cooling powers, respectively. To determine $\dot{Q}_{\mathrm{HS}, \mathrm{CCHP}}$ and $\dot{Q}_{\mathrm{HS}, \mathrm{SS}}$, it is necessary to know the efficiency of (1) a reference power plant, (2) a reference heating system, and (3) a reference cooling system. Considering the reference efficiencies for the electric, heating, and cooling systems, the PESR can be expressed as:

$$
\text { PESR }=1-\frac{\dot{Q}_{\mathrm{HS}, \mathrm{CCHP}}}{\frac{\left|\dot{W}_{\mathrm{net}}\right|}{\eta_{\mathrm{re}, \mathrm{e}}}+\frac{\left|\dot{Q}_{\mathrm{M}}\right|}{\eta_{\mathrm{ref}, \mathrm{h}}}+\frac{\dot{Q}_{\mathrm{C}}}{\eta_{\mathrm{re}, \mathrm{e}, \mathrm{ref}, \mathrm{c}}}}
$$

This is illustrated in Figure 12.

Regarding the reference power plant and its efficiency, the EU regulation No. $2015 / 2402^{51}$ establishes that the harmonized efficiency reference for the production of electricity using solid biomass is $\eta_{\mathrm{th}, \mathrm{e}}=0.30$, assuming $15^{\circ} \mathrm{C}$ as ambient temperature and a heat source temperature of $300{ }^{\circ} \mathrm{C}$. However, the 


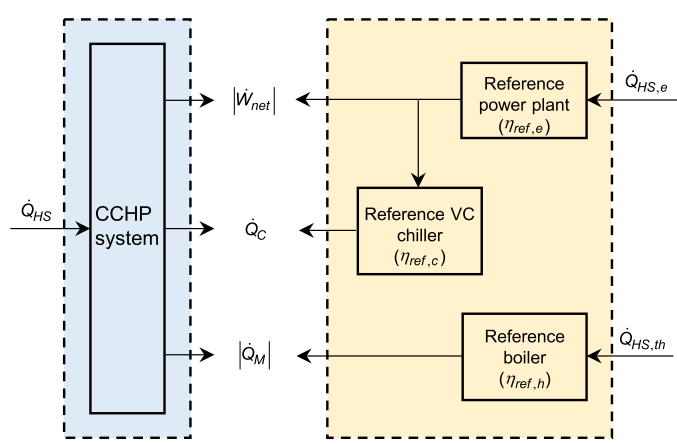

Figure 12. Illustration of the comparison between conventional generation and trigeneration systems.

temperature levels considered in this work are 20 and $150^{\circ} \mathrm{C}$. It would be thus unfair to consider the same efficiency. To overcome this problem, it is proposed to calculate the ratio between the reference plant considered by the EU regulation and a Carnot engine operating at the considered temperature levels. Then, this ratio can be used to obtain the efficiency of a reference power plant whose temperature levels are 15 and 150 ${ }^{\circ} \mathrm{C}$.

The thermal efficiency of a Carnot engine operating between 15 and $300{ }^{\circ} \mathrm{C}$ is 0.50 , i.e., the ORC plant considered by the EU regulation No. $2015 / 2402^{51}$ runs at $60 \%$ of the efficiency of the corresponding Carnot engine. For the temperature levels considered in this work $\left(20-150{ }^{\circ} \mathrm{C}\right)$, the Carnot efficiency is equal to 0.31 . In consequence, the thermal efficiency of the reference power plant for PESR calculations is $\eta_{\text {ref,e }}=0.31 \times 0.6$ $=0.19$.

In turn, the reference heating system is a biomass-fueled boiler, in which the heat generated by biomass combustion is utilized to produce hot water or steam to satisfy heat needs. For the sake of simplicity, it is assumed that the harmonized efficiency reference for the production of heat is the same for hot water or steam generation. The EU regulation No. 2015/2402 $2^{51}$ sets this value at $\eta_{\text {ref,h }}=0.86$.

Finally, for the reference cooling system, the EU regulation No. $2016 / 2281^{52}$ introduces an indicator named seasonal space cooling energy efficiency $\left(\eta_{\mathrm{S}, \mathrm{C}}\right)$ as a benchmark parameter for cooling systems. It is defined as the reference annual cooling demand pertaining to the cooling season covered by a cooling system and the annual energy consumption for cooling. This parameter considers the varying weather conditions during the year. Therefore, it could be assumed as an average coefficient of performance (COP). For electric, air-to-air air conditioners, this value is set to $\eta_{\mathrm{ref,c}}=\eta_{\mathrm{s}, \mathrm{c}}=2.57$.

\section{CASE STUDIES AND OPERATING SPECIFICATIONS}

Two case studies related to different CCHP end-users are investigated to assess the impact of operating conditions on the list of promising working fluids. The underlying equations described in Section 3 are the same for both case studies. The only differences among them are specifications.

For both case studies, the heat source temperature is $160{ }^{\circ} \mathrm{C}$. For the sake of simplicity, it is assumed that the overall required duty by the end-users is equal to $100 \mathrm{~kW}\left(\left|\dot{W}_{\text {net }}\right|+\left|\dot{Q}_{M}\right|+\dot{Q}_{C}=\right.$ $\dot{m}\left(\left|w_{\text {net }}\right|+\left|q_{\mathrm{M}}\right|+q_{\mathrm{C}}\right)$. In addition, the cooling, heating, and electric needs are quantified as a percentage of the total duty requirements. It is worth noting that the overall required duty of $100 \mathrm{~kW}$ is a calculation basis.
5.1. Case Study 1: Residential/Commercial User. For case study 1 , it is assumed that for the residential/commercial users:

- The cooling needs include air-conditioning, and they represent $30 \%$ of the total duty. Comfort temperatures in summer range between 20 and $25^{\circ} \mathrm{C}$. To reach such temperatures, the working fluid should enter the evaporator II at $10{ }^{\circ} \mathrm{C}$, i.e., at $20{ }^{\circ} \mathrm{C}$ decreased by the pinch point temperature.

- The heating needs account for $40 \%$ of the total duty and are related to space heating or hot water requirements. Heating power is commonly required at $90^{\circ} \mathrm{C}$.

- The electric power required to drive machines, devices, and essential equipment reaches the remaining $30 \%$ of the total duty.

The distribution of cooling, heating, and power needs is based on ref 53.

5.2. Case Study 2: Food Industry. For case study 2, it is assumed that for the food industry:

- The cooling needs include food storage and preservation, and they represent $20 \%$ of the total duty. The set-point temperature within fridges is usually maintained between 2 and $5{ }^{\circ} \mathrm{C}$. To reach such temperatures, the working fluid should enter the evaporator II at $-10{ }^{\circ} \mathrm{C}$.

- The heating needs, in turn, represent $60 \%$ of the total duty and are related to the production of low-pressure steam or to specific processes such as pasteurization. Heating power is commonly required at $130{ }^{\circ} \mathrm{C}$.

- The electric power required to drive machines, devices, and essential equipment reach the remaining $20 \%$ of the total duty.

The distribution of cooling, heating, and power needs are based on the work of Compton et al. ${ }^{54}$

The resulting screening criteria and the relevant process conditions for both case studies are summarized in Tables 3 and 4 , respectively.

Table 3. Summary of Filtering Criteria

\begin{tabular}{|c|c|c|c|}
\hline step & criterion & $\begin{array}{l}\text { case study } 1 \\
\text { residential/commercial }\end{array}$ & $\begin{array}{l}\text { case study } 2 \\
\text { food industry }\end{array}$ \\
\hline 1 & $T_{\text {crit }}$ & \multicolumn{2}{|c|}{$>155^{\circ} \mathrm{C}$} \\
\hline 2 & $T_{\mathrm{tp}}$ & $<5^{\circ} \mathrm{C}$ & $<-15^{\circ} \mathrm{C}$ \\
\hline 3 & $P^{\text {sat }} @ T_{\mathrm{C}}$ & $>750$ mbar@10 ${ }^{\circ} \mathrm{C}$ & $>750$ mbar @ - $10{ }^{\circ} \mathrm{C}$ \\
\hline 4 & $\rho_{\mathrm{dv}} @ T_{\mathrm{C}}$ & $>0.01 \mathrm{~kg} / \mathrm{m}^{3} @ 10^{\circ} \mathrm{C}$ & $>0.01 \mathrm{~kg} / \mathrm{m}^{3} @-10{ }^{\circ} \mathrm{C}$ \\
\hline 5 & $P^{\text {sat }} @ T_{\mathrm{H}}$ & \multicolumn{2}{|c|}{$<35$ bar @ $150^{\circ} \mathrm{C}$} \\
\hline 6 & toxicity & \multicolumn{2}{|c|}{ exclude categories 1,2 and 3 of acute toxicity } \\
\hline 7 & GWP & \multicolumn{2}{|c|}{$<150$} \\
\hline 8 & ODP & \multicolumn{2}{|c|}{$<10^{-3}$} \\
\hline 9 & AIT & \multicolumn{2}{|c|}{$>240^{\circ} \mathrm{C}$} \\
\hline 10 & $\begin{array}{l}\text { material } \\
\text { compatibility }\end{array}$ & \multicolumn{2}{|c|}{ compatible at least with steel } \\
\hline
\end{tabular}

\section{RESULTS}

6.1. Screening Results. The progress of compound elimination from the initial pool of 2540 candidates for the considered case studies is given in Table 5 .

The critical temperature filter eliminates almost 150 molecules for both case studies. This filter screened out very light molecules such as oxygen, nitrogen, or hydrogen, as well as alkanes, alkenes, and alkynes with less than 4 carbon atoms. 
Table 4. Summary of Operating Specifications ${ }^{a}$

\begin{tabular}{|c|c|c|c|c|}
\hline parameter & symbol & units & $\begin{array}{c}\text { case study } 1 \\
\text { residential/commercial }\end{array}$ & $\begin{array}{c}\text { case study } 2 \\
\text { food industry }\end{array}$ \\
\hline overall duty & & $\mathrm{kW}$ & 100 & \\
\hline $\begin{array}{l}\text { heating power } \\
\text { share }\end{array}$ & $\left|\dot{Q}_{M}\right|$ & $\mathrm{kW}$ & 40 & 60 \\
\hline $\begin{array}{l}\text { cooling power } \\
\text { share }\end{array}$ & $\dot{Q}_{C}$ & $\mathrm{~kW}$ & 30 & 20 \\
\hline $\begin{array}{l}\text { electric power } \\
\text { share }\end{array}$ & $\left|\dot{W}_{\text {net }}\right|$ & $\mathrm{kW}$ & 30 & 20 \\
\hline $\begin{array}{l}\text { state } 1: \\
\quad \text { temperature }\end{array}$ & $T_{1}$ & ${ }^{\circ} \mathrm{C}$ & $20^{\circ} \mathrm{C}$ & \\
\hline $\begin{array}{l}\text { state 1: vapor } \\
\text { quality }\end{array}$ & $x_{1}$ & & 0.0 & \\
\hline state 2: pressure & $P_{2}$ & bar & $P^{\text {sat }}\left(150^{\circ} \mathrm{C}\right)$ & \\
\hline $\begin{array}{l}\text { state 3: } \\
\text { temperature }\end{array}$ & $T_{3}$ & ${ }^{\circ} \mathrm{C}$ & 150 & \\
\hline $\begin{array}{l}\text { state 3: vapor } \\
\text { quality }\end{array}$ & $x_{3}$ & & 1.0 & \\
\hline state 4: pressure & $P_{4}$ & bar & $P^{\text {sat }}\left(90^{\circ} \mathrm{C}\right)$ & $P^{\text {sat }}\left(130^{\circ} \mathrm{C}\right)$ \\
\hline $\begin{array}{l}\text { state 5: } \\
\quad \text { temperature }\end{array}$ & $T_{5}$ & ${ }^{\circ} \mathrm{C}$ & $90{ }^{\circ} \mathrm{C}$ & $130^{\circ} \mathrm{C}$ \\
\hline $\begin{array}{l}\text { state 6: } \\
\text { temperature }\end{array}$ & $T_{6}$ & ${ }^{\circ} \mathrm{C}$ & $20^{\circ} \mathrm{C}$ & \\
\hline $\begin{array}{l}\text { state } 7: \\
\quad \text { temperature }\end{array}$ & $T_{7}$ & ${ }^{\circ} \mathrm{C}$ & $20^{\circ} \mathrm{C}$ & \\
\hline $\begin{array}{l}\text { state } 7 \text { : vapor } \\
\text { quality }\end{array}$ & $x_{7}$ & & 0.0 & \\
\hline $\begin{array}{l}\text { state } 8: \\
\text { temperature }\end{array}$ & $\mathrm{T}_{8}$ & ${ }^{\circ} \mathrm{C}$ & $10{ }^{\circ} \mathrm{C}$ & $-10^{\circ} \mathrm{C}$ \\
\hline $\begin{array}{l}\text { state } 9: \\
\text { temperature }\end{array}$ & $T_{9}$ & ${ }^{\circ} \mathrm{C}$ & $10^{\circ} \mathrm{C}$ & $-10^{\circ} \mathrm{C}$ \\
\hline state 10: pressure & $P_{10}$ & bar & $P^{\mathrm{sat}}\left(20^{\circ} \mathrm{C}\right)$ & \\
\hline $\begin{array}{l}\text { isentropic } \\
\text { efficiency of } \\
\text { turbine I and II }\end{array}$ & $\eta_{\mathrm{T}, \mathrm{I}} / \eta_{\mathrm{T}, \mathrm{II}}$ & & 0.75 & \\
\hline $\begin{array}{l}\text { isentropic } \\
\text { efficiency of } \\
\text { turbine III }\end{array}$ & $\eta_{\mathrm{T}, \mathrm{III}}$ & & 0.65 & \\
\hline $\begin{array}{l}\text { isentropic } \\
\text { efficiency of } \\
\text { compressor }\end{array}$ & $\eta_{\mathrm{C}}$ & & 0.65 & \\
\hline $\begin{array}{l}\text { isentropic } \\
\text { efficiency of } \\
\text { pump }\end{array}$ & $\eta_{\mathrm{P}}$ & & 0.85 & \\
\hline
\end{tabular}

$a_{(*)}$ The specification in bold was selected to fulfill the degree of freedom.

Table 5. Progress of the Number of Compounds Passing the Successive Filters from the Initial Pool of 2540 Candidates for the Two Considered Case Studies

\begin{tabular}{|c|c|c|c|c|}
\hline step & criterion & $\begin{array}{l}\text { case study } 1 \\
\text { residential/commercial }\end{array}$ & $\begin{array}{c}\text { case } \\
\text { study } 2 \\
\text { food } \\
\text { industry }\end{array}$ & $\begin{array}{l}\text { case study } 2: \\
\text { relaxed } \\
\text { constraint } \\
(\text { filter } 3)\end{array}$ \\
\hline 0 & initial count & \multicolumn{3}{|c|}{2540 (fluids) } \\
\hline 1 & $T_{\text {crit }}$ & 2394 & \multicolumn{2}{|c|}{2394} \\
\hline 2 & $T_{\mathrm{tp}}$ & 1568 & \multicolumn{2}{|c|}{1465} \\
\hline 3 & $P^{\text {sat }} @ T_{\mathrm{C}}$ & 40 & 5 & 39 \\
\hline 4 & $\rho_{\mathrm{dv}} @ T_{\mathrm{C}}$ & 40 & 5 & 39 \\
\hline 5 & $P^{\mathrm{sat}} @ T_{\mathrm{H}}$ & 24 & 0 & 23 \\
\hline 6 & toxicity & 10 & 0 & 10 \\
\hline 7 & GWP & 10 & 0 & 10 \\
\hline 8 & ODP & 10 & 0 & 10 \\
\hline 9 & AIT & 9 & 0 & 9 \\
\hline 10 & $\begin{array}{l}\text { material } \\
\text { compatibility }\end{array}$ & 9 & 0 & 9 \\
\hline
\end{tabular}

Well-known high-GWP refrigerants such as HCFC-22, HFC-32, HFC-134a, and HFC-143a were eliminated. Furthermore, lowGWP molecules, including HFO-1234ze(E), HFO-1234ze(Z), HCFO-1336mzz(E), HFO-1234yf, or HFO-1234zf, were excluded.

The triple-point temperature constraint eliminated almost 830 (case study 1) and 930 (case study 2) additional compounds from different chemical families. Among the excluded molecules, very heavy molecules were found in both cases (e.g., alkanes and alkenes with more than 14 carbons). Moreover, a wide range of aromatic compounds, from benzene $\left(\mathrm{C}_{6} \mathrm{H}_{6}\right)$ to naphthacene $\left(\mathrm{C}_{18} \mathrm{H}_{12}\right)$, were also eliminated. In a general trend, oxygenated compounds (acids, ketones, aldehydes) with more than 2 carbon and 2 oxygen atoms, nitrogenated compounds with more than 6 carbon atoms, sulfur molecules with more than 4 carbon atoms, as well as halogenated compounds with more than 2 bromine, chlorine, and/or iodine atoms were excluded.

It was observed that the minimum operating pressure $\left(P^{\text {sat }}\left(T_{\mathrm{C}}\right)\right)$ was a very constraining criterion. In Figure 13 , the

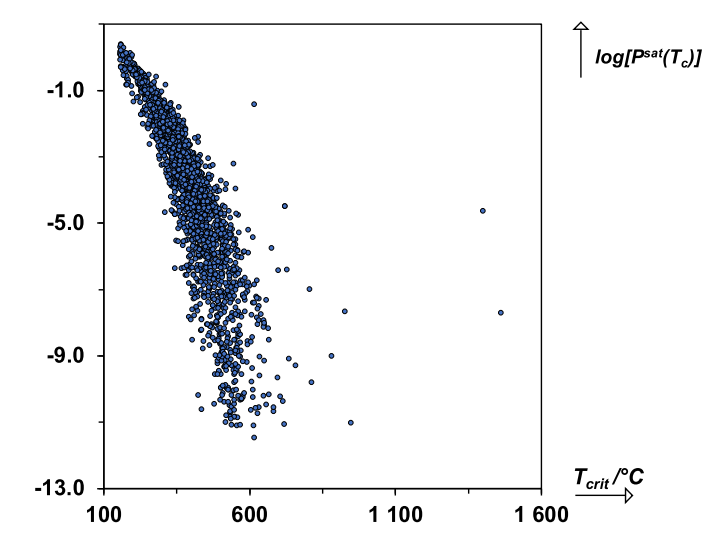

Figure 13. Saturation pressure at $T_{\mathrm{C}}=10^{\circ} \mathrm{C}$ versus critical temperature for the 1568 molecules remaining after filter 2 for case study 1 .

vapor pressure at $T_{\mathrm{C}}=10{ }^{\circ} \mathrm{C}$ is plotted against critical temperature for the 1568 molecules remaining after filter 2 for case study 1 . It is possible to observe that working fluids with higher values of $T_{\text {crit }}$ operate at lower pressures (implying a higher risk of air infiltration into the system). Only 40 of the 1568 fluids have $P^{\text {sat }}\left(T_{\mathrm{C}}\right)$ higher than the typical lower bound pressure limit of $750 \mathrm{mbar}$ (also selected in this work, see Table 3). It is interesting to remark that refrigerants (i.e., used in purely refrigeration/cooling applications) do not have critical temperatures larger than $105^{\circ} \mathrm{C}^{25}$ to avoid too low operating pressures at evaporating temperatures ranging from -20 to $5{ }^{\circ} \mathrm{C}$. Nevertheless, the filter on $T_{\text {crit }}$ for CCHP applications was set to $155{ }^{\circ} \mathrm{C}$ with the aim of absorbing heat from a source at 160 ${ }^{\circ} \mathrm{C}$. This shows that the objective of supplying work, heat, and cold with a single working fluid represents, per se, a highly selective condition.

In addition, screening for case study 2 showed that no molecule of the design space can meet the specified requirements. It was decided to relax the filter on $P_{\min }$ to obtain exactly the same number of molecules as in case 1 at the end of the screening procedure. It was found necessary to impose $P_{\min }=P^{\text {sat }}$ $\left(T_{\mathrm{C}}\right)$ higher than 325 mbar to obtain a final list of 9 molecules. It is worth recalling that the initial constraint for $P_{\min }\left(P_{\min } \geq 750\right.$ mbar) was already "relaxed". The new condition may be critical since the investment needed for the construction of well-sealed 
devices to avoid air infiltration into the cycle could seriously impact the machine cost. This should be considered very carefully because one of the requirements of decentralized energy systems is that their components must be simple and easy to manufacture and design. ${ }^{23}$

At this point, it is interesting to have a look at common reference fluids used in ORC systems that were excluded during the screening process for the two cases studies. For instance, $n$ pentane, isopentane, HFC- $365 \mathrm{mfc}$, and toluene are excluded due to their low minimum pressure (see Table 6). It should be

Table 6. Minimum Operating Pressures $\left(P^{\text {sat }}\left(T_{\mathrm{C}}\right)\right)$ of Four Reference Fluids for the Two Considered Case Studies

\begin{tabular}{lcc}
\multicolumn{1}{c}{ molecules } & $P_{\min }=P^{\text {sat }}\left(10^{\circ} \mathrm{C}\right) / \mathrm{mbar}$ & $P_{\min }=P^{\text {sat }}\left(-10^{\circ} \mathrm{C}\right) / \mathrm{mbar}$ \\
$n$-pentane & 382 & 152 \\
isopentane & 523 & 220 \\
HFC-365mfc & 296 & 105 \\
toluene & 17 & 5 \\
\hline
\end{tabular}

noted that these fluids are rarely condensed at temperatures lower than $30-40{ }^{\circ} \mathrm{C}$, while in these work conditions required for the supply of cooling power can reach $-10{ }^{\circ} \mathrm{C}$. It is worth noting that beyond the minimal pressure criterion, $\mathrm{HFC}-365 \mathrm{mfc}$ would still have been eliminated due to its high GWP.

The maximum pressure filter excluded 16 additional fluids. The maximum value in pressure is reached by $\mathrm{SO}_{2}$ with around 70 bar. A promising molecule (nonflammable, nontoxic) is HFC-143, but it exceeds the constraint by almost 11 bar. Next, the toxicity filter rejected several chlorinated compounds due to their carcinogenic or acutely toxic character. Examples of such molecules are ethyl chloride, HCFC-11, phosgene $\left(\mathrm{CCl}_{2} \mathrm{O}\right)$, dichlorosilane $\left(\mathrm{Cl}_{2} \mathrm{H}_{2} \mathrm{Si}\right)$, and boron trichloride $\left(\mathrm{BCl}_{3}\right)$.

Finally, filters on ODP and GWP did not exclude any molecule among the remaining ones after filter 6 , while the constraint on AIT only eliminated methyl ethyl ether. The final list of 9 promising candidates is presented in Table 7 . The wellknown trade-off between flammability and environmental impact is observed. ${ }^{35,39}$ To reduce the GWP and ODP, molecules should be less halogenated, which implies that flammability increases. It is observed that to satisfy constraints on GWP and ODP, 7 over 9 fluids are extremely flammable, while the 2 remaining ones are nonflammable. In addition, among these fluids, none of them belongs to categories 1,2 , or 3 of acute toxicity.

6.2. Performance Results. In this section, the performances in terms of EUF and $Q_{V}$ for the final nine working fluids are evaluated. The results are summarized in Figure 14 and Table 8. The accuracy of the $t c$-PR model on the properties of interest such as vapor pressure, density, and enthalpy of vaporization is presented in Table 9. Since "optimal" molecules are those that exhibit high EUF and high $Q_{V}$, the inverses of such indicators are plotted so that candidates satisfying both objectives lie at the lower left corner of the figure.

(1) Cyclobutane gives the best EUF for both case studies. No special toxicological issues are associated with it according to the GHS classification. It has no ODP and a negligible GWP. However, cyclobutane is an extremely flammable fluid and may be the less stable molecule of the list as a consequence of angle strain related to its bonds. Furthermore, a CCHP system operating with cyclobutane could experience air infiltration because the minimal pressure of the cycle is lower than atmospheric pressure.

(2) 1-Butene-3-yne (vinylacetylene) exhibits the greatest volumetric capacity and its EUF is only 2\% lower compared to cyclobutane. It does not have issues concerning ODP and GWP. As well as cyclobutane, it is an extremely flammable molecule. From the constructional standpoint, it has a minimum pressure of around $1.18 \mathrm{bar}$, which guarantees that air does not enter into the system during operation. Nevertheless, it has the lowest AIT among the whole list of fluids and it could have stability problems since it contains double and triple bonds.

(3) The refrigerant HFC-152 has similar capabilities as 1butene-3-yne in terms of EUF. It is nontoxic, has a low GWP (53) and zero ODP. HFC-152 should not present problems concerning stability due to the presence of fluorine atoms and the absence of unsaturated bonds. As well as for 1-butene-3-yne, CCHP systems containing HFC-152 do not have issues related to air infiltration. It is worth noting that Preißinger et al. ${ }^{39}$ found that this fluid

Table 7. List of 9 Candidates Passing the Screening Filters for the Two Considered Case Studies ${ }^{a}$

\begin{tabular}{|c|c|c|c|c|c|c|c|c|c|}
\hline CAS & name & formula & SMILES & $\begin{array}{l}\text { ASHRAE } \\
\text { designation }\end{array}$ & GWP & ODP & $\begin{array}{c}\text { flammability } \\
\text { category }\end{array}$ & $\begin{array}{l}T_{\text {crit }} \\
\left({ }^{\circ} \mathrm{C}\right)\end{array}$ & $\begin{array}{l}P_{\text {crit }} \\
\text { (bar) }\end{array}$ \\
\hline \multicolumn{10}{|c|}{ alkanes, alkenes, alkynes } \\
\hline $463-82-1$ & neopentane & $\mathrm{C}_{5} \mathrm{H}_{12}$ & $\mathrm{CC}(\mathrm{C})(\mathrm{C}) \mathrm{C}$ & & $<1$ & 0 & 1 & 160.65 & 31.96 \\
\hline $590-19-2$ & 1,2-butadiene & $\mathrm{C}_{4} \mathrm{H}_{6}$ & $\mathrm{C}=\mathrm{C}=\mathrm{CC}$ & & $<1$ & 0 & 1 & 178.85 & 43.60 \\
\hline $590-18-1$ & cis-2-butene & $\mathrm{C}_{4} \mathrm{H}_{8}$ & $\mathrm{C} / \mathrm{C}=\mathrm{C} \backslash \backslash \mathrm{C}$ & & $<1$ & 0 & 1 & 162.35 & 42.10 \\
\hline $689-97-4$ & vinylacetylene & $\mathrm{C}_{4} \mathrm{H}_{4}$ & $\mathrm{C}=\mathrm{CC} \# \mathrm{C}$ & & $<1$ & 0 & 1 & 180.85 & 48.60 \\
\hline \multicolumn{10}{|c|}{ cycloalkanes, cycloalkenes, cycloalkynes } \\
\hline $287-23-0$ & cyclobutane & $\mathrm{C}_{4} \mathrm{H}_{8}$ & $\mathrm{C} 1 \mathrm{CCC} 1$ & & $<1$ & 0 & 1 & 186.78 & 49.80 \\
\hline \multicolumn{10}{|c|}{ fluorinated alkanes } \\
\hline $624-72-6$ & 1,2-difluoroethane & $\mathrm{C}_{2} \mathrm{H}_{4} \mathrm{~F}_{2}$ & FCCF & HFC-152 & 53 & 0 & 1 & 171.85 & 43.40 \\
\hline \multicolumn{10}{|c|}{ halogenated alkenes (fluorine plus chlorine) } \\
\hline $\begin{array}{l}102687- \\
65-0\end{array}$ & $\begin{array}{l}\text { (E)-1-chloro-3,3,3-trifluoro-1- } \\
\text { propene }\end{array}$ & $\mathrm{C}_{3} \mathrm{H}_{2} \mathrm{ClF}_{3}$ & $\mathrm{C}(/ \mathrm{C}=\mathrm{C} / \mathrm{Cl})(\mathrm{F})(\mathrm{F}) \mathrm{F}$ & $\begin{array}{l}\text { HCFO- } \\
1233 \mathrm{zd}(E)\end{array}$ & 4 & 0.0004 & 4 & 166.45 & 36.24 \\
\hline $\begin{array}{l}111512- \\
60-8\end{array}$ & $\begin{array}{c}(Z) \text {-1-chloro-2,3,3,3- } \\
\text { tetrafluoropropene }\end{array}$ & $\mathrm{C}_{3} \mathrm{HClF}_{4}$ & $\begin{array}{l}\mathrm{C}(=\mathrm{C}(\backslash \mathrm{C}(\mathrm{F})(\mathrm{F}) \mathrm{F}) / \\
\mathrm{F}) / \mathrm{Cl}\end{array}$ & $\begin{array}{l}\text { HCFO- } \\
1224 \mathrm{yd}(\mathrm{Z})\end{array}$ & 1 & 0.0002 & 4 & 155.54 & 33.37 \\
\hline \multicolumn{10}{|c|}{ silanes } \\
\hline $993-07-7$ & trimethyl silane & $\mathrm{C}_{3} \mathrm{H}_{10} \mathrm{Si}$ & $\mathrm{C}[\mathrm{SiH}](\mathrm{C})(\mathrm{C})$ & & $<1$ & 0 & 1 & 158.85 & 31.90 \\
\hline
\end{tabular}

${ }^{a}$ Filter on $P_{\min }$ for case study 2 is relaxed. 

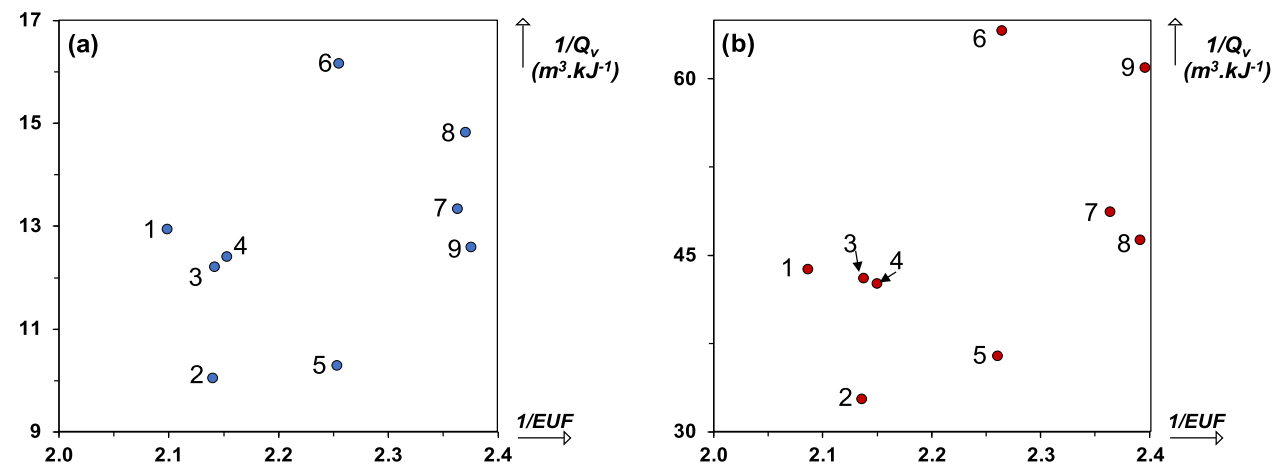

Figure 14. Inverse of volumetric capacity versus the inverse of the energy utilization factor for the 9 molecules remaining after the screening procedure: (a) case study 1 and (b) case study 2. The numbers correspond to the ranking of each molecule, as shown in Table 8.

Table 8. CCHP Cycle Performances for the Nine Candidates Passing the Screening Filters ${ }^{a}$

\begin{tabular}{|c|c|c|c|c|c|c|c|c|c|}
\hline \multicolumn{5}{|c|}{ case study 1} & \multicolumn{5}{|c|}{ case study 2} \\
\hline name/ASHRAE designation & rank & EUF & $Q_{v}\left(\mathrm{~kJ} \cdot \mathrm{m}^{-3}\right)$ & $\overline{\text { PESR (\%) }}$ & name/ASHRAE designation & rank & EUF & $Q_{v}\left(\mathrm{~kJ} \cdot \mathrm{m}^{-3}\right)$ & PESR (\%) \\
\hline cyclobutane & 1 & 0.4766 & 772.9 & 23.0 & cyclobutane & 1 & 0.4794 & 228.1 & 5.4 \\
\hline vinylacetylene & 2 & 0.4673 & 995.5 & 21.5 & vinylacetylene & 2 & 0.4683 & 304.6 & 3.1 \\
\hline HFC- 152 & 3 & 0.4669 & 819.1 & 21.4 & HFC- 152 & 3 & 0.4679 & 232.1 & 3.1 \\
\hline 1,2-butadiene & 4 & 0.4645 & 805.8 & 21.0 & 1,2-butadiene & 4 & 0.4653 & 234.7 & 2.5 \\
\hline cis-2-butene & 5 & 0.4438 & 971.1 & 17.4 & cis-2-butene & 5 & 0.4425 & 274.2 & -2.5 \\
\hline HCFO-1233zd(E) & 6 & 0.4435 & 618.6 & 17.3 & HCFO-1233zd $(E)$ & 6 & 0.4418 & 156.0 & -2.7 \\
\hline neopentane & 7 & 0.4232 & 749.9 & 13.3 & neopentane & 7 & 0.4232 & 205.3 & -7.2 \\
\hline HCFO-1224yd(Z) & 8 & 0.4219 & 674.6 & 13.1 & trimethyl silane & 8 & 0.4183 & 215.8 & -8.4 \\
\hline trimethyl silane & 9 & 0.421 & 794.0 & 12.9 & HCFO-1224yd(Z) & 9 & 0.4176 & 164.0 & -8.6 \\
\hline
\end{tabular}

Table 9. Parameters Corresponding to the tc-PR Model and the Mean Absolute Percentage Average (MAPE) on the Properties of Interest for the Nine Candidates Passing the Screening Filters ${ }^{a}$

\begin{tabular}{|c|c|c|c|c|c|c|c|c|c|c|c|c|c|}
\hline name & $L$ & $M$ & $N$ & $\left(\begin{array}{c}c \\
\left(\mathrm{~cm}^{3} \cdot \mathrm{mol}^{-1}\right)\end{array}\right.$ & $\begin{array}{c}\text { MAPE } \\
\text { on }_{P}^{\text {sat }} \\
(\%)\end{array}$ & $T_{\min }(\mathrm{K})$ & $T_{\max }(\mathrm{K})$ & $\begin{array}{c}\text { MAPE } \\
\text { on } \\
\Delta_{\text {vap }} H \\
(\%)\end{array}$ & $T_{\min }(\mathrm{K})$ & $T_{\max }(\mathrm{K})$ & $\begin{array}{c}\text { MAPE } \\
\text { on } \rho_{\text {sat }}^{\text {sat }} \\
(\%)\end{array}$ & $T_{\min }(\mathrm{K})$ & $T_{\max }(\mathrm{K})$ \\
\hline neopentane & 0.1268 & 0.8494 & 2.5591 & -5.9633 & 0.21 & 256.60 & 433.80 & 1.66 & 256.60 & 425.12 & 1.37 & 256.60 & 390.42 \\
\hline 1,2-butadiene & 1.1829 & 0.9640 & 0.5059 & 4.4542 & 1.61 & 234.20 & 452.00 & 2.45 & 136.95 & 442.96 & 1.48 & 136.95 & 406.80 \\
\hline cis-2-butene & 0.4528 & 0.8193 & 1.1794 & -1.3958 & 0.40 & 228.32 & 435.50 & 1.32 & 134.26 & 426.79 & 1.40 & 134.26 & 391.95 \\
\hline vinylacetylene & 1.6720 & 0.8480 & 0.3360 & 3.1708 & 4.18 & 231.48 & 454.00 & 1.39 & 173.15 & 444.92 & 2.00 & 173.15 & 408.60 \\
\hline cyclobutane & 0.2137 & 0.8638 & 2.0678 & -2.3922 & 0.11 & 235.06 & 459.93 & 1.80 & 182.48 & 450.73 & 3.12 & 182.48 & 413.94 \\
\hline HFC-152 & 0.8080 & 0.8640 & 0.7967 & 22.5137 & 1.63 & 234.28 & 445.00 & 4.02 & 215.00 & 436.10 & 5.13 & 179.60 & 400.50 \\
\hline $\begin{array}{l}\text { HCFO- } \\
1233 \mathrm{zd}(E)\end{array}$ & 0.5136 & 0.9352 & 1.5679 & -1.3501 & 0.86 & 237.15 & 439.60 & & & & 1.23 & 300.00 & 395.64 \\
\hline $\begin{array}{l}\text { HCFO- } \\
1224 \mathrm{yd}(\mathrm{Z})\end{array}$ & 0.4724 & 0.9129 & 1.7702 & 0.2541 & 1.32 & 300.00 & 428.69 & & & & 1.14 & 300.00 & 385.82 \\
\hline trimethyl silane & 1.0052 & 1.0000 & 0.6166 & -3.3422 & 0.54 & 229.02 & 432.00 & 1.35 & 137.26 & 423.36 & 1.24 & 137.26 & 388.80 \\
\hline
\end{tabular}

was a promising candidate for ORC for mobile applications.

(4) 1,2-Butadiene performs similarly as 1-butene-3-yne and HFC-152 in terms of EUF and exhibits a $20 \%$ loss in $Q_{v}$ compared with 1-butene-3-yne. It fulfills environmental and toxicological criteria. Furthermore, CCHP cycles operating with 1,2-butadiene have a slight subatmospheric minimum pressure. However, this fluid is a cumulated diene, characterized by the adjacent carboncarbon double bonds, and tends to be unstable.

(5) Cis-2-butene yields a 7\% loss in EUF compared to cyclobutane and only a $2.5 \%$ loss in $Q_{V}$ compared to 1 butene-3-yne. It has negligible GWP, no ODP, and does not provoke serious adverse health effects. It displays an excellent minimum pressure (1.23 bar) and guarantees the tightness of the device.

(6) $\operatorname{HCFO}-1233 \mathrm{zd}(E)$ also achieves a 7\% loss in EUF with respect to cyclobutane but has the worst volumetric capacity among the list of fluids. Nevertheless, it has the advantage of being nonflammable, nontoxic, and having low GWP (4) and ODP (equal to 0.0004). Furthermore, it has been well-investigated and some authors (e.g., Eyerer et al. $^{48}$ ) studied the possibility of using it as a dropin replacement of HFC-245fa in ORC systems. Moreover, they showed that HCFO-1233zd(E) is compatible with common polymers, namely, ethylene-propylene-diene rubber (EPDM), fluororubber (FKM), nitrile-butadiene rubber (NBR), and chlorobutadiene rubber (CR), used in 
ORC systems. Concerning constructional constraints, it is worth noting that it has the lowest minimum operating pressure (785 mbar), which could result in important costs to avoid air infiltration.

(7) Neopentane (2,2-dimethylpropane) presents a reduction of about $11 \%$ in EUF compared to cyclobutane and $25 \%$ in $Q_{v}$ with respect to 1-butene-3-yne. It is extremely flammable and has negligible GWP and no ODP. Furthermore, CCHP systems containing neopentane should not have issues related to sealing tightness since its minimum operating pressure is around 1.03 bar.

(8) Compared to cyclobutane, HCFO-1224yd( $Z$ ) has a loss of 11.5 and $32 \%$ in EUF and $Q_{\text {, }}$, respectively. As HCFO$1233 \mathrm{zd}(E)$, it has low GWP (1) and ODP (0.0002). Moreover, it is nonflammable and nontoxic. It has also been studied by Eyerer and co-workers ${ }^{48}$ as a drop-in candidate for the replacement of HFC-245fa in ORC systems.

(9) Trimethyl silane has the worst performance in terms of EUF and achieves (compared to cyclobutane) a 20\% loss in volumetric capacity. It is extremely flammable and has negligible GWP and no ODP. It fulfills toxicological constraints as well as constructional requirements.

Concerning the PESR for case study 1 , the nine fluids reach positive values for this indicator, i.e., all of them lead to savings of primary energy compared to the use of separated systems for each objective. On the other hand, for case study 2, only the top 4 molecules of the list enable to reduce the consumption of primary energy.

\section{CONCLUSIONS}

In the present work, a product design approach for the selection of suitable working fluids for novel combined heating, cooling, and power applications has been presented. In addition, the $\mathrm{CCHP}$ cycle has been described as a transition from a power to a (power + heating) to a (power + heating + cooling) cycle. This is accompanied by a degree-of-freedom analysis.

The main conclusions of this work are:

- Concerning the working-fluid selection, a database search has been implemented to screen about 60000 species included in the DDB, the DIPPR, and the NIST TDE $103 \mathrm{~b}$ databases. The screening approach considered thermodynamic, process-related, constructional, safety, and environmental constraints. Moreover, the $t c-\mathrm{PR}$ model has been used for the first time to ensure the quality of the calculation of thermophysical properties while providing a high level of accuracy for the target properties and the performance assessment of promising working fluids.

- The screening coupled with the performance evaluation has demonstrated that flammable fluids such as vinylacetylene or HFC-152 have a good potential for CCHP applications. In the case where highly constraining safety restrictions are imposed, HCFO-1233zd(E) could be an interesting candidate since it is nonflammable and nontoxic.

- Furthermore, the results revealed antagonism between the objectives of single-fluid CCHP systems. This is reflected by the fact that fluids with higher critical temperatures, and, thus, potentially better in terms of energy utilization, will lead to constructional problems since they operate at too low pressures in the evaporator at which cooling power is supplied.

Finally, it is worth recalling that the study has intended to give an overview of promising working fluids, which should be considered for further theoretical and experimental investigations. This work opens the way to implement database search methodologies to find suitable working fluids for more sophisticated CCHP applications.

This work provides an original and comprehensive workingfluid design approach enabling the selection of the most appropriate working fluid for CCHP systems, over a large number of fluids, and a wide number of design conditions and constraints. Additionally, further research should address the development of two-phase expanders and compressors to guarantee the scale-up of this architecture of CCHP systems.

\section{ASSOCIATED CONTENT}

\section{Supporting Information}

The Supporting Information is available free of charge at https://pubs.acs.org/doi/10.1021/acssuschemeng.1c03362.

Appendix A1: Derivation of the efficiency of the Carnot cycle.

Appendix A2: The effect of lowering the vapor quality at the exit of the vapor generator on the thermal efficiency of an ideal Rankine cycle (PDF)

\section{AUTHOR INFORMATION}

\section{Corresponding Authors}

Silvia Lasala - Université de Lorraine, Ecole Nationale Supérieure des Industries Chimiques, Laboratoire Réactions et Génie des Procédés (UMR CNRS 7274), 54000 Nancy,

France; Email: silvia.lasala@univ-lorraine.fr

Jean-Noël Jaubert - Université de Lorraine, École Nationale Supérieure des Industries Chimiques, Laboratoire Réactions et Génie des Procédés (UMR CNRS 7274), 54000 Nancy, France; (1) orcid.org/0000-0001-7831-5684; Email: jeannoel.jaubert@univ-lorraine.fr

\section{Authors}

Andrés Piña-Martinez - Université de Lorraine, Ecole Nationale Supérieure des Industries Chimiques, Laboratoire Réactions et Génie des Procédés (UMR CNRS 7274), 54000 Nancy, France

Romain Privat - Université de Lorraine, Ecole Nationale Supérieure des Industries Chimiques, Laboratoire Réactions et Génie des Procédés (UMR CNRS 7274), 54000 Nancy, France; (1) orcid.org/0000-0001-6174-9160

Véronique Falk - Université de Lorraine, Ecole Nationale Supérieure des Industries Chimiques, Laboratoire Réactions et Génie des Procédés (UMR CNRS 7274), 54000 Nancy, France

Complete contact information is available at:

https://pubs.acs.org/10.1021/acssuschemeng.1c03362

\section{Notes}

The authors declare no competing financial interest.

\section{ACKNOWLEDGMENTS}

This work has been developed in the context of the European Project REGEN-BY-2, funded from the European Union's Horizon 2020 research and innovation program under grant agreement No. 851541. 


\section{REFERENCES}

(1) Electricity - Global Energy Review 2020 - Analysis. https:// www.iea.org/reports/global-energy-review-2020/electricity (accessed April 13th, 2021).

(2) Briola, S. Plant and Method for the Supply of Electric Power and/ or Mechanical Power, Heating Power and/or Cooling Power. WO2017158511A1, September 21, 2017.

(3) Briola, S.; Di Marco, P.; Gabbrielli, R. Thermodynamic Sensitivity Analysis of a Novel Trigeneration Thermodynamic Cycle with TwoPhase Expanders and Two-Phase Compressors. Energy 2017, 127, $335-350$.

(4) Mokadam, R. G. Cooling Apparatus and Process. US3621667A, November 23, 1971.

(5) Fabris, G. Rotating Single Cycle Two-Phase Thermally Activated Heat Pump. US5216899A, June 8, 1993.

(6) Maraver, D.; Quoilin, S.; Royo, J. Optimization of BiomassFuelled Combined Cooling, Heating and Power (CCHP) Systems Integrated with Subcritical or Transcritical Organic Rankine Cycles (ORCs). Entropy 2014, 16, 2433-2453.

(7) Maraver, D.; Royo, J.; Lemort, V.; Quoilin, S. Systematic Optimization of Subcritical and Transcritical Organic Rankine Cycles (ORCs) Constrained by Technical Parameters in Multiple Applications. Appl. Energy 2014, 117, 11-29.

(8) Bell, I. H.; Wronski, J.; Quoilin, S.; Lemort, V. Pure and PseudoPure Fluid Thermophysical Property Evaluation and the Open-Source Thermophysical Property Library CoolProp. Ind. Eng. Chem. Res. 2014, 53, 2498-2508.

(9) Hong, X.; Shi, F. Comparative Analysis of Small-Scale Integrated Solar ORC-Absorption Based Cogeneration Systems. Energies 2020, 13, 946 .

(10) Lemmon, E. W.; Huber, M. L.; McLinden, M. O. NIST Standard Reference Database 23: Reference Fluid Thermodynamic and Transport Properties-REFPROP, version 9.1, 2013.

(11) Al-Sulaiman, F. A.; Dincer, I.; Hamdullahpur, F. Exergy Modeling of a New Solar Driven Trigeneration System. Sol. Energy 2011, 85, 2228-2243.

(12) Huang, Y.; Wang, Y. D.; Rezvani, S.; McIlveen-Wright, D. R.; Anderson, M.; Mondol, J.; Zacharopolous, A.; Hewitt, N. J. A TechnoEconomic Assessment of Biomass Fuelled Trigeneration System Integrated with Organic Rankine Cycle. Appl. Therm. Eng. 2013, 53, 325-331.

(13) Briola, S.; Gabbrielli, R.; Fino, A.; Bischi, A.; Di Marco, P. Working Fluid Selection and Extensive Sensitivity Analysis for the Thermodynamic Optimization of a Novel Trigeneration Cycle with Two-Phase Expanders and Compressors. Energy 2019, 179, 709-726.

(14) Jaubert, J.-N.; Privat, R.; Le Guennec, Y.; Coniglio, L. Note on the Properties Altered by Application of a Péneloux-Type Volume Translation to an Equation of State. Fluid Phase Equilib. 2016, 419, 8895.

(15) Privat, R.; Jaubert, J.-N.; Le Guennec, Y. Incorporation of a Volume Translation in an Equation of State for Fluid Mixtures: Which Combining Rule? Which Effect on Properties of Mixing? Fluid Phase Equilib. 2016, 427, 414-420.

(16) Le Guennec, Y.; Lasala, S.; Privat, R.; Jaubert, J.-N. A Consistency Test for $\alpha$-Functions of Cubic Equations of State. Fluid Phase Equilib. 2016, 427, 513-538.

(17) Le Guennec, Y.; Privat, R.; Lasala, S.; Jaubert, J.-N. On the Imperative Need to Use a Consistent $\alpha$-Function for the Prediction of Pure-Compound Supercritical Properties with a Cubic Equation of State. Fluid Phase Equilib. 2017, 445, 45-53.

(18) Le Guennec, Y.; Privat, R.; Jaubert, J.-N. Development of the Translated-Consistent $t c-\mathrm{PR}$ and $t c$-RK Cubic Equations of State for a Safe and Accurate Prediction of Volumetric, Energetic and Saturation Properties of Pure Compounds in the Sub- and Super-Critical Domains. Fluid Phase Equilib. 2016, 429, 301-312.

(19) Pina-Martinez, A.; Le Guennec, Y.; Privat, R.; Jaubert, J.-N.; Mathias, P. M. Analysis of the Combinations of Property Data That Are Suitable for a Safe Estimation of Consistent Twu $\alpha$-Function Parameters: Updated Parameter Values for the Translated-Consistent
tc-PR and tc-RK Cubic Equations of State. J. Chem. Eng. Data 2018, 63, $3980-3988$

(20) Moggridge, G. D.; Cussler, E. L. An Introduction to Chemical Product Design. Chem. Eng. Res. Des. 2000, 78, 5-11.

(21) Gani, R. Chemical Product Design: Challenges and Opportunities. Comput. Chem. Eng. 2004, 28, 2441-2457.

(22) Zhang, L.; Mao, H.; Liu, Q.; Gani, R. Chemical Product Design Recent Advances and Perspectives. Curr. Opin. Chem. Eng. 2020, 27, $22-34$.

(23) Quoilin, S.; Broek, M. V. D.; Declaye, S.; Dewallef, P.; Lemort, V. Techno-Economic Survey of Organic Rankine Cycle (ORC) Systems. Renewable Sustainable Energy Rev. 2013, 22, 168-186.

(24) Bao, J.; Zhao, L. A Review of Working Fluid and Expander Selections for Organic Rankine Cycle. Renewable Sustainable Energy Rev. 2013, 24, 325-342.

(25) Mota-Babiloni, A.; Makhnatch, P.; Khodabandeh, R. Recent Investigations in HFCs Substitution with Lower GWP Synthetic Alternatives: Focus on Energetic Performance and Environmental Impact. Int. J. Refrig. 2017, 82, 288-301.

(26) Joback, K. G. Designing Molecules Possessing Desired Physical Property Values. Thesis, Massachusetts Institute of Technology, 1989.

(27) Joback, K.; Stephanopoulos, G. Designing Molecules Possessing Desired Physical Property-Values; Siirola, J.; Grossmann, I.; Stephanopoulos, G., Eds.; Elsevier Science Publ B V: Amsterdam, 1990.

(28) Gani, R.; Nielsen, B.; Fredenslund, A. A Group Contribution Approach to Computer-Aided Molecular Design. AIChE J. 1991, 37, $1318-1332$

(29) Duvedi, A. P.; Achenie, L. E. K. Designing Environmentally Safe Refrigerants Using Mathematical Programming. Chem. Eng. Sci. 1996, $51,3727-3739$.

(30) Ourique, J. E.; Silva Telles, A. Computer-Aided Molecular Design with Simulated Annealing and Molecular Graphs. Comput. Chem. Eng. 1998, 22, S615-S618.

(31) Marcoulaki, E. C.; Kokossis, A. C. On the Development of Novel Chemicals Using a Systematic Optimisation Approach. Part II. Solvent Design. Chem. Eng. Sci. 2000, 55, 2547-2561.

(32) Sahinidis, N. V.; Tawarmalani, M.; Yu, M. R. Design of Alternative Refrigerants via Global Optimization. AIChE J. 2003, 49, $1761-1775$.

(33) Samudra, A. P.; Sahinidis, N. V. Optimization-Based Framework for Computer-Aided Molecular Design. AIChE J. 2013, 59, 36863701.

(34) Kazakov, A.; McLinden, M. O.; Frenkel, M. Computational Design of New Refrigerant Fluids Based on Environmental, Safety, and Thermodynamic Characteristics. Ind. Eng. Chem. Res. 2012, 51, 1253712548.

(35) McLinden, M. O.; Kazakov, A. F.; Brown, J. S.; Domanski, P. A. A Thermodynamic Analysis of Refrigerants: Possibilities and Tradeoffs for Low-GWP Refrigerants. Int. J. Refrig. 2014, 38, 80-92.

(36) Papadopoulos, A. I.; Stijepovic, M.; Linke, P. On the Systematic Design and Selection of Optimal Working Fluids for Organic Rankine Cycles. Appl. Therm. Eng. 2010, 30, 760-769.

(37) Palma-Flores, O.; Flores-Tlacuahuac, A.; Canseco-Melchor, G. Optimal Molecular Design of Working Fluids for Sustainable LowTemperature Energy Recovery. Comput. Chem. Eng. 2015, 72, 334349.

(38) Lampe, M.; Stavrou, M.; Schilling, J.; Sauer, E.; Gross, J.; Bardow, A. Computer-Aided Molecular Design in the Continuous-Molecular Targeting Framework Using Group-Contribution PC-SAFT. Comput. Chem. Eng. 2015, 81, 278-287.

(39) Preißinger, M.; Schwöbel, J. A. H.; Klamt, A.; Brüggemann, D. Multi-Criteria Evaluation of Several Million Working Fluids for Waste Heat Recovery by Means of Organic Rankine Cycle in Passenger Cars and Heavy-Duty Trucks. Appl. Energy 2017, 206, 887-899.

(40) Bowskill, D. H.; Tropp, U. E.; Gopinath, S.; Jackson, G.; Galindo, A.; Adjiman, C. S. Beyond a Heuristic Analysis: Integration of Process and Working-Fluid Design for Organic Rankine Cycles. Mol. Syst. Des. Eng. 2020, 5, 493-510. 
(41) Gani, R.; Dam-Johansen, K.; Ng, K. M. Chemical Product Design - A Brief Overview. In Computer Aided Chemical Engineering; Ng, K. M.; Gani, R.; Dam-Johansen, K., Eds.; Chemical Product Design: Toward a Perspective Through Case Studies; Elsevier, 2007; Chapter 1, Vol. 23, pp 1-20.

(42) Bolton, E. E.; Wang, Y.; Thiessen, P. A.; Bryant, S. H. PubChem: Integrated Platform of Small Molecules and Biological Activities. In Annual Reports in Computational Chemistry; Wheeler, R. A.; Spellmeyer, D. C., Eds.; Elsevier, 2008; Chapter 12, Vol. 4, pp 217-241.

(43) Directive 2014/34/EU of the European Parliament and of the Council of 26 February 2014 on the Harmonisation of the Laws of the Member States Relating to Equipment and Protective Systems Intended for Use in Potentially Explosive Atmospheres (Recast) Text with EEA Relevance; Vol. OJ L.

(44) Hodnebrog, Ø.; Etminan, M.; Fuglestvedt, J. S.; Marston, G.; Myhre, G.; Nielsen, C. J.; Shine, K. P.; Wallington, T. J. Global Warming Potentials and Radiative Efficiencies of Halocarbons and Related Compounds: A Comprehensive Review. Rev. Geophys. 2013, $51,300-378$.

(45) Organization (WMO), W. M.; Administration, (NOAA) National Oceanic and Atmospheric; Programme, (UNEP) United Nations Environment; Administration, (NASA) National Aeronautics and Space; Commission, E.; World Meteorological Organization (WMO). GORMP, 58. Scientific Assessment of Ozone Depletion: 2018; Technical Document. WMO: Geneva, 2018.

(46) The European Parliament and the Council of the European Union. Regulation (EU) No 517/2014 of the European Parliament and the Council of 16 April 2014 on Fluorinated Greenhouse Gases and Repealing Regulation (EC) No 842/2006. J. Eur. Union 2014, 150; pp 195-230.

(47) Regulation (EC) No 1005/2009 of the European Parliament and of the Council of 16 September 2009 on Substances That Deplete the Ozone Layer (Text with EEA Relevance), 2009; Vol. 286.

(48) Eyerer, S.; Dawo, F.; Kaindl, J.; Wieland, C.; Spliethoff, H. Experimental Investigation of Modern ORC Working Fluids R1224yd(Z) and R1233zd(E) as Replacements for R245fa. Appl. Energy 2019, 240, 946-963.

(49) Twu, C. H.; Bluck, D.; Cunningham, J. R.; Coon, J. E. A Cubic Equation of State with a New Alpha Function and a New Mixing Rule. Fluid Phase Equilib. 1991, 69, 33-50.

(50) Piña-Martinez, A.; Privat, R.; Lasala, S.; Soave, G.; Jaubert, J.-N. Search for the Optimal Expression of the Volumetric Dependence of the Attractive Contribution in Cubic Equations of State. Fluid Phase Equilib. 2020, 522, No. 112750.

(51) Commission Delegated Regulation (EU) 2015/2402 of 12 October 2015 Reviewing Harmonised Efficiency Reference Values for Separate Production of Electricity and Heat in Application of Directive 2012/27/EU of the European Parliament and of the Council and Repealing Commission Implementing Decision 2011/877/EU, 2015; Vol. 333.

(52) Commission Regulation (EU) 2016/2281 of 30 November 2016 Implementing Directive 2009/125/EC of the European Parliament and of the Council Establishing a Framework for the Setting of Ecodesign Requirements for Energy-Related Products, with Regard to Ecodesign Requirements for Air Heating Products, Cooling Products, High Temperature Process Chillers and Fan Coil Units (Text with EEA Relevance), 2016; Vol. 346.

(53) Macchi, E.; Silva, P.; Campanari, S. La Microcogenerazione a Gas Naturale; Polipress: Milano, 2006.

(54) Compton, M.; Willis, S.; Rezaie, B.; Humes, K. Food Processing Industry Energy and Water Consumption in the Pacific Northwest. Innovative Food Sci. Emerging Technol. 2018, 47, 371-383. 